\title{
Synthesis and Bioassay of Amino-pyrazolone, Amino-isoxazolone and Amino-pyrimidinone Derivatives
}

\author{
Venkatapuram Padmavathi, ${ }^{*}$ Dandu Rangayapalle Chinna Venkata Subbaiah, Konda Mahesh, and \\ Thunga RADHA LAKSHMI
}

Department of Chemistry, Sri Venkateswara University; Tirupati-517 502, India.

Received July 24, 2007; accepted September 25, 2007

\begin{abstract}
Novel amino-pyrazolone, amino-isoxazolone and amino-pyrimidinone derivatives were prepared from ethyl 4-phenylsulfonyl-2-(2'-phenylsulfonylethyl)-2-cyanobutyrate (1), ethyl 4-arylsulfonyl-3-aryl-2-cyanobutyrate (7) and ethyl 4-arylmethylsulfonyl-3-aryl-2-cyanobutyrate (8). The lead molecules have been tested for their antimicrobial activity and antioxidant property.
\end{abstract}

Key words amino-pyrazolone; amino-isoxazolone; amino-pyrimidinone; antimicrobial activity; antioxidant property

Heterocyclic compounds particularly five and six membered heterocycles have attracted the attention of pharmaceutical community over the years due to their therapeutic value. A number of barbiturate and thiobarbiturate derivatives exhibit anticonvulsant, anaesthetic, sedative and hypnotic properties. $^{1-5)}$ In fact, phenobarbital and mephobarbital ${ }^{6}$ are used for clinical treatment of epilepsy. Barbiturates still are used world wide in hospitals as injection narcotics. $\left.{ }^{78}\right) \mathrm{Be}-$ sides this, pyrazole and isoxazole derivatives possess bacteriostatic, antidiabetic, analgesic, antiarrhythmic, anti-inflammatory, antifungal and antiviral properties. ${ }^{9-14)}$ Celecoxib, a pyrazole derivative, and valdecoxib, an isoxazole derivative are now being used as anti-inflammatory drugs. ${ }^{15)} \mathrm{A}$ continuoues effort is maintained in our laboratories for the development of biologically potent heterocycles. The present communication deals with the synthesis of amino substituted pyrimidine, thioxopyrimidine, pyrazoline and isoxazoline derivatives from Michael adducts by cyclocondensation with different nucleophiles.

\section{Chemistry}

The Michael adduct, ethyl 4-phenylsulfonyl-2-(2'-phenylsulfonylethyl)-2-cyanobutyrate (1) is prepared by the addition of ethyl cyanoacetate to vinyl sulfone in the presence of Trition-B in benzene. However, ethyl 4-arylsulfonyl-3-aryl-2cyanobutyrate (7) and ethyl 4-arylmethylsulfonyl-3-aryl-2cyanobutyrate (8) are obtained by the reaction of aryl styryl sulfones and benzyl styryl sulfones with ethyl cyanoacetate in the presence of $\mathrm{K}_{2} \mathrm{CO}_{3}$ in methyl ethyl ketone. ${ }^{16)}$ The cyclocondensation of 1,7 and 8 with hydrazine hydrate in the presence of piperidine in ethanol afforded 5-amino-4,4bis-(2'-phenylsulfonylethyl)-pyrazol-3-one (2), 5-amino-4(2'-arylsulfonyl-1'-arylethyl)-pyrazol-3-one (9) and 5amino-4-(2'-arylmethylsulfonyl-1' -arylethyl)-pyrazol-3-one (10). Similarly, 3-amino-4,4-bis-(2'-phenylsulfonylethyl)isoxazol-5-one (3), 3-amino-4-(2'-arylsulfonyl-1'-arylethyl)isoxazol-5-one (11) and 3-amino-4-( $2^{\prime}$-arylmethylsulfonyl1 '-arylethyl)-isoxazol-5-one (12) are obtained by treating $\mathbf{1}$, 7 and 8 with hydroxylamine hydrochloride. Likewise, six membered heterocycles, 6-amino-5,5-bis-(2'-phenylsulfonylethyl)-2-hydroxypyrimidine-4-one (4), 6-amino-5-(2'arylsulfonyl-1'-arylethyl)-2-hydroxypyrimidine-4-one (13), 6-amino-5-(2'-arylmethylsulfonyl-1' -arylethyl)-2-hydroxypyrimidine-4-one (14), 6-imino-5,5-bis-( $2^{\prime}$-phenylsul- fonylethyl)-1,3-dimethylpyrimidine-2,4-dione (5), 6-imino-5(2'-arylsulfonyl-1' -arylethyl)-1,3-dimethylpyrimidine-2,4dione (15) and 6-imino-5-(2'-arylmethylsulfonyl-1' arylethyl)-1,3-dimethylpyrimidine-2,4-dione (16) are obtained by the cyclocondensation of $\mathbf{1 , 7}$ and 8 with urea and 1,3-dimethylurea, respectively. In addition, 6-amino-5,5-bis(2'-phenylsulfonylethyl)-2-mercaptopyrimidine-4-one (6), 6amino-5-(2'-arylsulfonyl-1' -arylethyl)-2-mercaptopyrimidine-4-one (17) and 6-amino-5-(2'-arylmethylsulfonyl-1'arylethyl)-2-mercaptopyrimidine-4-one (18) are prepared by refluxing the compounds 1, 7 and 8 with thiourea. Summary of the reactions involved in the synthesis is given in Charts 1 and 2.

The IR spectra of 2-6 and 9-18 displayed an absorption band at $3435-3475$ and $3345-3370 \mathrm{~cm}^{-1}$ for $\mathrm{NH}_{2}$ and at $1125-1145$ and $1310-1340 \mathrm{~cm}^{-1}$ for $\mathrm{SO}_{2}$. Apart from these compounds $\mathbf{4 - 6}$ and $\mathbf{1 3}-\mathbf{1 8}$ exhibited an absorption band at $1645-1682 \mathrm{~cm}^{-1}(\mathrm{C}=\mathrm{O}$ of pyrimidine ring $)$ while $\mathbf{6}$, 17 and 18 exhibited a band at $2545-2560 \mathrm{~cm}^{-1}$ (SH). Besides the compounds $2-\mathbf{4}, \mathbf{6}, \mathbf{9}-\mathbf{1 4}, \mathbf{1 7}$ and 18 showed an absorption band at $1600-1620 \mathrm{~cm}^{-1}(\mathrm{C}=\mathrm{N})$. In the ${ }^{1} \mathrm{H}-$ NMR spectra of $\mathbf{2}-\mathbf{6}$ the methylene protons displayed multiplets at $1.83-2.01,2.11-2.23$ for $\mathrm{C}_{1}^{\prime}-\mathrm{H}$ and 2.80 $3.05 \mathrm{ppm}$ for $\mathrm{C}_{2}^{\prime}-\mathrm{H}$. However, a singlet is observed at 2.70 $2.74 \mathrm{ppm}$ due to $N$-methyl protons in $\mathbf{5}$. The compounds $\mathbf{2}, \mathbf{3}$, 4 and 6 exhibited a broad singlet at $5.77-5.97 \mathrm{ppm}$ for $\mathrm{NH}_{2}$. Also the compounds 2 and $\mathbf{5}$ showed a broad singlet at $9.18-9.96 \mathrm{ppm}$ for $\mathrm{NH}$. The signals due to $\mathrm{NH}_{2}$ and $\mathrm{NH}$ disappeared on deuteration. The ${ }^{1} \mathrm{H}-\mathrm{NMR}$ spectra of $\mathbf{9 - 1 2}$ displayed a doublet at $4.29-4.44 \mathrm{ppm}$ for $\mathrm{C}_{4}-\mathrm{H}$ while $\mathbf{1 3}-\mathbf{1 8}$ at $4.31-4.35 \mathrm{ppm}$ for $\mathrm{C}_{5}-\mathrm{H}$. The compounds $\mathbf{9}-\mathbf{1 8}$ showed a multiplet in the region $4.08-4.29 \mathrm{ppm}$ for $\mathrm{C}_{1}^{\prime}-\mathrm{H}$, two double doublets at $3.01-3.13$ and $3.68-3.78 \mathrm{ppm}$ for $\mathrm{C}_{2}^{\prime}-\mathrm{H}$. a broad singlet at $5.77-5.91 \mathrm{ppm}$ is observed for $\mathrm{NH}_{2}$ in 9 14,17 and 18 . The compounds $10,12,14,16$ and 18 showed a sharp singlet at $4.25-4.35 \mathrm{ppm}$ for benzylic protons.

Antimicrobial Testing The compounds 2-6 and 9-18 were tested for in vitro antimicrobial activity against the Gram-positive bacteria Staphylococcus aureus, Bacillus subtilis, the Gram-negative bacteria Klebsiella pneumoniae, Proteus vulgaris and fungi Fusarium solani, Curvularia lunata and Aspergillus niger. The primary screen was carried out by agar disc-diffusion method ${ }^{17)}$ using nutrient agar medium. The minimal inhibitory concentration for the most active 


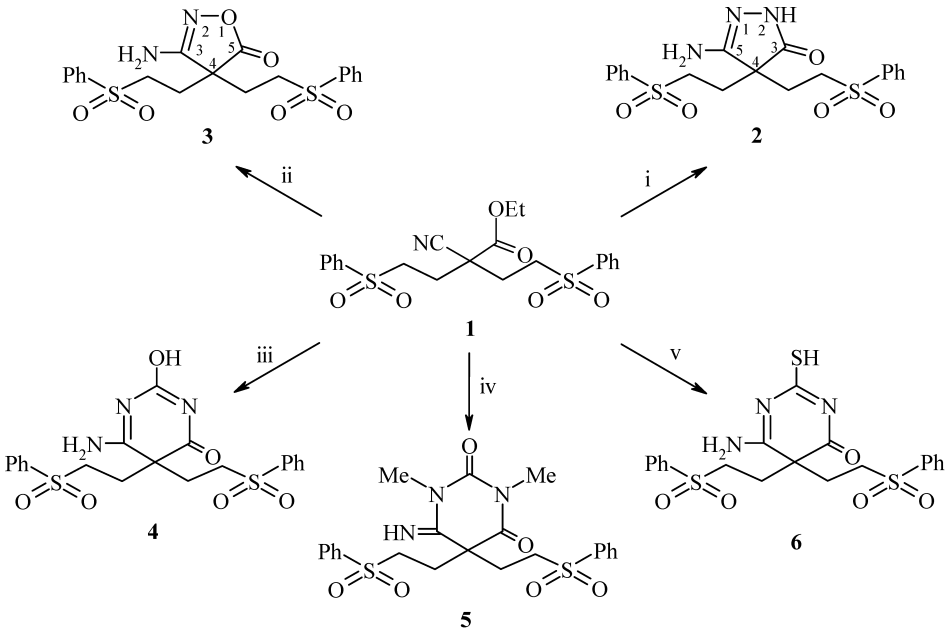

(i) $\mathrm{NH}_{2} \mathrm{NH}_{2} \cdot \mathrm{H}_{2} \mathrm{O}$, Piperidine, EtOH, reflux, 6-8 h, $85 \%$

(ii) $\mathrm{NH}_{2} \mathrm{OH} . \mathrm{HCl}$, Piperidine, EtOH, reflux, $4-5 \mathrm{~h}, 65 \%$ (iii) $\mathrm{NH}_{2} \mathrm{CONH}_{2}$, Piperidine, EtOH, reflux, 6-9 h, 66\%

(iv) MeNHCONHMe, Piperidine, EtOH, reflux, 6-10 h, 64\% (v) $\mathrm{NH}_{2} \mathrm{CSNH}_{2}$, Piperidine, EtOH, reflux, 7-12 h, 68\%

Chart 1<smiles>[Y]C(CC(C)C)C1C(=O)ON=C1N</smiles>

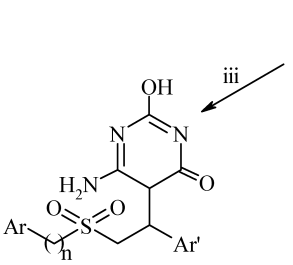

$13 / 14$<smiles>[Y]C(CS(=O)(=O)O)C1C(=O)NN=C1N</smiles><smiles>[Y]C(CS(=O)(=O)O)C(C#N)C(=O)OCC</smiles><smiles>CCCCC</smiles><smiles>[Y]C(CC(C)C)C1C(=O)N=C(S)N=C1N</smiles>

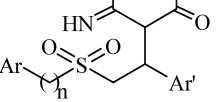

$15 / 16$ $\mathrm{n}=0(\mathbf{7 , 9 , 1 1 , 1 3 , 1 5 , 1 7 )}$ $\mathrm{n}=1(\mathbf{8}, 10,12,14,16,18)$

$\begin{array}{lll} & \mathrm{Ar} & \mathrm{Ar} \\ \mathbf{7 , 9 , 1 1 , 1 3 , 1 5 , 1 7}: \mathbf{a} & \mathrm{Ph} & \mathrm{Ph} \\ \mathbf{7 , 9 , 1 1 , 1 3 , 1 5 , 1 7}: \mathbf{b} & \mathrm{Ph} & 4-\mathrm{Cl} . \mathrm{Ph} \\ \mathbf{8 , 1 0 , 1 2 , 1 4 , 1 6 , 1 8 :}: \mathbf{a} & \text { 4-Cl.Ph } & \mathrm{Ph} \\ \mathbf{8 , 1 0 , 1 2 , 1 4 , 1 6 , 1 8 :} \text { b } & \text { 4-Cl.Ph } & \text { 4-Cl.Ph }\end{array}$

(i) $\mathrm{NH}_{2} \mathrm{NH}_{2} \cdot \mathrm{H}_{2} \mathrm{O}$, Piperidine, EtOH, reflux, 6-8 h, 78-86\%

(ii) $\mathrm{NH}_{2} \mathrm{OH} . \mathrm{HCl}$, Piperidine, EtOH, reflux, $4-5$ h, $67-73 \%$ (iii) $\mathrm{NH}_{2} \mathrm{CONH}_{2}$, Piperidine, EtOH, reflux, 6-9 h, 66-70\% (iv) MeNHCONHMe, Piperidine, EtOH, reflux, 6-10 h, 62-65\% (v) $\mathrm{NH}_{2} \mathrm{CSNH}_{2}$, Piperidine, EtOH, reflux, 7-12 h, 65-75\%

\section{Chart 2}

compounds 2 and 10a against the same microorganisms used in the preliminary screening was carried out using microdilution susceptibility method. ${ }^{18)}$ Chloramphenicol and ketoconazole were used as control drugs. The observed data on the antimicrobial activity of the compounds and control drugs were given in Tables 1, 2 and 3 .

The results of the compounds of preliminary antibacterial testing are shown in Table 1 . The results revealed that majority of the synthesized compounds showed varying degrees of inhibition against the tested microorganisms. Among them 5-
Table 1. Antibacterial Activity of $\mathbf{2}-\mathbf{6}$ and $\mathbf{9 - 1 8}$

\begin{tabular}{|c|c|c|c|c|c|}
\hline \multirow{3}{*}{$\begin{array}{l}\text { Com- } \\
\text { pound }\end{array}$} & \multirow{3}{*}{$\begin{array}{l}\text { Concentra- } \\
\text { tion } \\
(\mu \mathrm{g})\end{array}$} & \multicolumn{4}{|c|}{ Zone of inhibition (mm) } \\
\hline & & \multicolumn{2}{|c|}{ Gram $(+)$ ve } & \multicolumn{2}{|c|}{ Gram $(-)$ ve } \\
\hline & & $\begin{array}{c}\text { Staphylococcus } \\
\text { aureus }\end{array}$ & $\begin{array}{c}\text { Bacillus } \\
\text { subtilis }\end{array}$ & $\begin{array}{c}\text { Klebsiella } \\
\text { pneumoniae }\end{array}$ & $\begin{array}{l}\text { Proteus } \\
\text { vulgaris }\end{array}$ \\
\hline \multirow[t]{2}{*}{2} & 100 & 34 & 36 & 29 & 27 \\
\hline & 200 & 39 & 38 & 33 & 31 \\
\hline \multirow[t]{2}{*}{3} & 100 & 28 & 26 & 25 & 29 \\
\hline & 200 & 32 & 30 & 26 & 31 \\
\hline \multirow[t]{2}{*}{4} & 100 & 16 & 14 & 15 & 16 \\
\hline & 200 & 18 & 17 & 18 & 18 \\
\hline \multirow[t]{2}{*}{5} & 100 & 14 & 13 & 11 & 12 \\
\hline & 200 & 17 & 15 & 14 & 15 \\
\hline \multirow[t]{2}{*}{6} & 100 & 20 & 17 & 18 & 16 \\
\hline & 200 & 23 & 21 & 20 & 19 \\
\hline \multirow[t]{2}{*}{ 9a } & 100 & 19 & 16 & 18 & 19 \\
\hline & 200 & 23 & 18 & 20 & 20 \\
\hline \multirow[t]{2}{*}{$10 \mathrm{a}$} & 100 & 32 & 37 & 33 & 31 \\
\hline & 200 & 37 & 39 & 36 & 34 \\
\hline \multirow[t]{2}{*}{$11 \mathrm{a}$} & 100 & 17 & 19 & 17 & 16 \\
\hline & 200 & 20 & 22 & 20 & 18 \\
\hline \multirow[t]{2}{*}{$12 \mathrm{a}$} & 100 & 27 & 28 & 27 & 26 \\
\hline & 200 & 31 & 33 & 29 & 29 \\
\hline \multirow[t]{2}{*}{ 13a } & 100 & 14 & 16 & 12 & 14 \\
\hline & 200 & 16 & 17 & 15 & 17 \\
\hline \multirow[t]{2}{*}{$14 a$} & 100 & 29 & 30 & 24 & 26 \\
\hline & 200 & 32 & 34 & 28 & 29 \\
\hline \multirow[t]{2}{*}{$15 a$} & 100 & 15 & 14 & 14 & 16 \\
\hline & 200 & 18 & 16 & 17 & 19 \\
\hline \multirow[t]{2}{*}{$16 \mathrm{a}$} & 100 & 12 & 11 & 16 & 14 \\
\hline & 200 & 15 & 13 & 18 & 17 \\
\hline \multirow[t]{2}{*}{$17 \mathrm{a}$} & 100 & 15 & 15 & 14 & 12 \\
\hline & 200 & 18 & 17 & 16 & 15 \\
\hline \multirow[t]{2}{*}{ 18a } & 100 & 18 & 20 & 16 & 16 \\
\hline & 200 & 21 & 22 & 20 & 18 \\
\hline \multirow{2}{*}{$\begin{array}{l}\text { Chloram- } \\
\text { phenicol }\end{array}$} & 100 & 35 & 38 & 37 & 42 \\
\hline & 200 & 41 & 44 & 42 & 45 \\
\hline
\end{tabular}

amino-4,4-bis-(2'-phenylsulfonylethyl)-pyrazol-3-one (2), 3amino-4,4-bis-(2'-phenylsulfonylethyl)-isoxazol-5-one (3), 5-amino-4-[2'-(4-chlorophenylmethylsulfonyl)-1' -(phenyl)- 
ethyl]-pyrazol-3-one (10a), 3-amino-4-[2'-(4-chlorophenylmethylsulfonyl)-1'-(phenyl)ethyl]-isoxazol-5-one (12a) and 6-amino-5-[2'-(4-chlorophenylmethylsulfonyl)-1' -phenylethyl]-2-hydroxypyrimidine-4-one (14a) exhibited high activity $(24-39 \mathrm{~mm})$ on both gram $(+)$ ve and gram $(-)$ ve bacteria. In fact, compounds $\mathbf{2}$ and 10a showed pronounced activity $(36-39 \mathrm{~mm})$ towards gram $(+)$ ve bacteria. The compounds, 6-amino-5,5-bis-(2'-phenylsulfonylethyl)-2mercaptopyrimidine-4-one (6), 5-amino-4-(2'-phenylsulfonyl-1'-phenylethyl)-pyrazol-3-one (9a), 3-amino-4-(2'phenylsulfonyl-1'-phenylethyl)-isoxazol-5-one (11a) and 6amino-5-[2'-(4-chlorophenylmethylsulfonyl)-1' -phenylethyl)-2-mercaptopyrimidine-4-one (18a) displayed moderate to high activity towards gram $(+)$ ve bacteria $(16-23 \mathrm{~mm})$ and moderate activity $(16-20 \mathrm{~mm})$ towards gram $(-)$ ve bacteria. On the other hand, 6-amino-5,5-bis-(2'-phenylsulfonylethyl)-2-hydroxypyrimidine-4-one (4), 6-imino-5,5-bis-

Table 2. Antifungal Activity of $\mathbf{2}-\mathbf{6}$ and $\mathbf{9 - 1 8}$

\begin{tabular}{|c|c|c|c|c|}
\hline \multirow[b]{2}{*}{ Compound } & \multirow{2}{*}{$\begin{array}{c}\text { Concentration } \\
(\mu \mathrm{g})\end{array}$} & \multicolumn{3}{|c|}{ Zone of inhibition (mm) } \\
\hline & & $\begin{array}{l}\text { Fusarium } \\
\text { solani }\end{array}$ & $\begin{array}{l}\text { Curvularia } \\
\text { lunata }\end{array}$ & $\begin{array}{l}\text { Aspergillus } \\
\text { niger }\end{array}$ \\
\hline \multirow[t]{2}{*}{2} & 100 & 22 & 21 & 19 \\
\hline & 200 & 25 & 24 & 22 \\
\hline \multirow[t]{2}{*}{3} & 100 & 24 & 24 & 18 \\
\hline & 200 & 26 & 27 & 20 \\
\hline \multirow[t]{2}{*}{4} & 100 & 18 & 16 & 15 \\
\hline & 200 & 22 & 19 & 17 \\
\hline \multirow[t]{2}{*}{5} & 100 & 21 & 18 & 17 \\
\hline & 200 & 23 & 20 & 21 \\
\hline \multirow[t]{2}{*}{6} & 100 & 24 & 19 & 18 \\
\hline & 200 & 26 & 22 & 21 \\
\hline \multirow[t]{2}{*}{$9 a$} & 100 & 19 & 22 & 17 \\
\hline & 200 & 21 & 24 & 21 \\
\hline \multirow[t]{2}{*}{ 10a } & 100 & 28 & 25 & 20 \\
\hline & 200 & 31 & 27 & 23 \\
\hline \multirow[t]{2}{*}{$11 \mathrm{a}$} & 100 & 24 & 23 & 17 \\
\hline & 200 & 27 & 25 & 20 \\
\hline \multirow[t]{2}{*}{$12 \mathrm{a}$} & 100 & 29 & 27 & 22 \\
\hline & 200 & 32 & 31 & 24 \\
\hline \multirow[t]{2}{*}{ 13a } & 100 & 17 & 16 & 14 \\
\hline & 200 & 20 & 21 & 17 \\
\hline \multirow[t]{2}{*}{$14 \mathrm{a}$} & 100 & 18 & 21 & 16 \\
\hline & 200 & 20 & 23 & 19 \\
\hline \multirow[t]{2}{*}{$15 \mathbf{a}$} & 100 & 16 & 18 & 15 \\
\hline & 200 & 20 & 22 & 17 \\
\hline \multirow[t]{2}{*}{$16 a$} & 100 & 20 & 19 & 16 \\
\hline & 200 & 23 & 21 & 19 \\
\hline \multirow[t]{2}{*}{$17 \mathbf{a}$} & 100 & 16 & 17 & 15 \\
\hline & 200 & 19 & 19 & 16 \\
\hline \multirow[t]{2}{*}{ 18a } & 100 & 27 & 25 & 24 \\
\hline & 200 & 29 & 29 & 27 \\
\hline \multirow[t]{2}{*}{ Ketoconazole } & 100 & 38 & 41 & 36 \\
\hline & 200 & 42 & 44 & 39 \\
\hline
\end{tabular}

(2'-phenylsulfonylethyl)-1,3-dimethylpyrimidine-2,4-dione (5), 6-amino-5-(2'-phenylsulfonyl-1'-phenylethyl)-2-hydroxypyrimidine-4-one (13a), 6-imino-5-(2'-phenylsulfonyl-1'phenylethyl)-1,3-dimethylpyrimidine-2,4-dione (15a), 6imino-5-[2'-(4-chlorophenylmethylsulfonyl)-1'-phenylethyl]1,3-dimethylpyrimidine-2,4-dione (16a) and 6-amino-5-(2'phenylsulfonyl-1'-phenylethyl)-2-mercaptopyrimidine-4-one (17a) exhibited least activity against both bacteria.

Antifungal Testing All the test compounds inhibited the spore germination of tested fungi Aspergillus niger, Fusarium solani and Curvularia lunata. Results of the investigation presented in Table 2 revealed that all the compounds except $4,13 \mathrm{a}, 15 \mathrm{a}$ and $17 \mathrm{a}$ possess relatively high inhibitory effect on Fusarium solani and Curvularia lunata than on Aspergillus niger. Further, the compounds having aminopyrazolone and amino-isoxazolone units displayed greater activity.

The MIC values were determined as the lowest concentration that completely inhibited visible growth of the microorganisms (Table 3). The structure-antimicrobial activity relationship of the synthesized compounds revealed that the compounds having amino-hydroxypyrimidinone and $\mathrm{N}, \mathrm{N}$-dimethyliminopyrimidinedione exhibited least activity when compared with compounds having amino-pyrazolone and amino-isoxazolone moieties. Besides, the compounds having benzyl sulfonyl group were the most active. The maximum activity was observed with the compounds 2 and 10a having amino-pyrazolone unit (Table 3).

Antioxidant Testing The compounds 2-6 and 9-18 are tested for antioxidant property by nitric oxide ${ }^{19,20)}$ and $\mathrm{DPPH}^{21)}$ methods. The compounds $2, \mathbf{3}, \mathbf{1 0 a}$ and 12a exhibited high antioxidant property in both nitric oxide and DPPH

Table 4. Antioxidant Property of $\mathbf{2}-\mathbf{6}$ and $\mathbf{9}-\mathbf{1 8}$

\begin{tabular}{ccc}
\hline \hline & \multicolumn{2}{c}{ \% Inhibition at $100 \mu \mathrm{M}$} \\
\cline { 2 - 3 } Compound & Nitric oxide method & DPPH method \\
\hline $\mathbf{2}$ & 82.25 & 84.74 \\
$\mathbf{3}$ & 91.18 & 93.65 \\
$\mathbf{4}$ & 34.33 & 38.10 \\
$\mathbf{5}$ & 29.21 & 24.75 \\
$\mathbf{6}$ & 41.15 & 44.52 \\
$\mathbf{9 a}$ & 40.62 & 41.34 \\
$\mathbf{1 0 a}$ & 93.65 & 91.22 \\
$\mathbf{1 1 a}$ & 42.57 & 41.26 \\
$\mathbf{1 2 a}$ & 96.42 & 94.38 \\
$\mathbf{1 3 a}$ & 24.78 & 24.78 \\
$\mathbf{1 4 a}$ & 40.16 & 40.89 \\
$\mathbf{1 5 a}$ & 22.18 & 28.61 \\
$\mathbf{1 6 a}$ & 34.62 & 37.83 \\
$\mathbf{1 7}$ & 28.36 & 31.22 \\
$\mathbf{1 8 a}$ & 42.44 & 41.56 \\
\end{tabular}

Table 3. Minimum Inhibitory Concentration of $\mathbf{2}$ and 10a

\begin{tabular}{|c|c|c|c|c|c|c|c|}
\hline \multirow{2}{*}{ Compound } & \multicolumn{7}{|c|}{ Minimal inhibitory concentration (MIC), $\mu \mathrm{g} / \mathrm{ml}$} \\
\hline & S. aureus & B. subtilis & K. pneumoniae & P. vulgaris & F. solani & C. lunata & A. niger \\
\hline 2 & 100 & 100 & 200 & 200 & 100 & 100 & 100 \\
\hline $10 \mathrm{a}$ & 25 & 25 & 50 & 100 & 100 & 50 & 50 \\
\hline Chloramphenicol & 6.25 & 6.25 & 6.25 & 12.5 & - & - & - \\
\hline Ketoconazole & - & - & - & - & 12.5 & 6.25 & 6.25 \\
\hline
\end{tabular}


methods at $100 \mu \mathrm{M}$ concentration (Table 4).

\section{Conclusion}

A new class of amino-pyrazolone, amino-isoxazolone, and amino-pyrimidinone derivatives were prepared from Michael adducts 4-phenylsulfonyl-2-(2'-phenylsulfonylethyl)-2cyanobutyrate (1), ethyl 4-arylsulfonyl-3-aryl-2-cyanobutyrate (7) and ethyl 4-arylmethylsulfonyl-3-aryl-2-cyanobutyrate (8) by cyclocondensation with appropriate nucleophiles. The antimicrobial testing showed that compounds having amino-pyrazolone and amino-isoxazolone possess greater antibacterial activity.

\section{Experimental}

Melting points were determined in open capillaries on a Mel-Temp apparatus and are uncorrected. The purity of the compounds was checked by TLC (silica gel $\mathrm{H}, \mathrm{BDH}$, ethyl acetate/hexane, $3: 1$ ). The IR spectra were recorded on a Thermo Nicolet infrared spectrophotometer, model Nicolet IR-200 in $\mathrm{KBr}$ pellets. The ${ }^{1} \mathrm{H}-\mathrm{NMR}(300 \mathrm{MHz})$ and ${ }^{13} \mathrm{C}-\mathrm{NMR}(75.5 \mathrm{MHz})$ spectra were recorded in $\mathrm{CDCl}_{3} / \mathrm{DMSO}-d_{6}(1: 0.4)$ on a Varian EM-360 spectrometer with TMS as an internal standard. The elemental analyses were performed by using perkin-elmer 240c elemental analyzer. The mass spectra were recorded on Finnigan Mat 1210 B and Waters Micromass Quattro Micro API at $70 \mathrm{eV}$ with an emission current of $100 \mu \mathrm{A}$. The antioxidant property was carried out by using Shimadzu UV-2450 spectrophotometer. The compounds ethyl 4-phenylsulfonyl-2-(2'-phenylsulfonylethyl)-2cyanobutyrate (1), ethyl 4-arylsulfonyl-3-aryl-2-cyanobutyrate (7)/ethyl 4arylmethylsulfonyl-3-aryl-2-cyanobutyrate $(\mathbf{8})$ were prepared according to the literature procedure. ${ }^{16)}$

General Procedure of Synthesis of 5-Amino-4,4-bis-(2'-phenylsulfonylethyl)-pyrazol-3-one (2)/5-Amino-4-(2'-arylsulfonyl-1' -arylethyl)pyrazol-3-one $(9 \mathrm{a}-\mathrm{b}) / 5$-Amino-4-(2'-arylmethylsulfonyl-1' ${ }^{\prime}$-arylethyl)pyrazol-3-one (10a-b) A mixture of $\mathbf{1} / \mathbf{7} / \mathbf{8}(0.01 \mathrm{~mol})$, hydrazine hydrate $(0.015 \mathrm{~mol}), \mathrm{EtOH}(20 \mathrm{ml})$ and piperidine $(5 \mathrm{ml})$ was refluxed for $6-8 \mathrm{~h}$. The solution was cooled and poured onto crushed ice containing conc. $\mathrm{HCl}$. The reaction mixture was extracted with ethyl acetate. The organic layer was washed with brine, dried over anhydrous $\mathrm{Na}_{2} \mathrm{SO}_{4}$ and the solvent was removed under vacuum. The solid obtained was recrystallized from $\mathrm{MeOH}$.

5-Amino-4,4-bis-(2'-phenylsulfonylethyl)-pyrazol-3-one (2): White crystals; yield $85 \%, \mathrm{mp} 209-211^{\circ} \mathrm{C}$; IR $(\mathrm{KBr}) \mathrm{cm}^{-1}$ : 3475, $3369\left(\mathrm{NH}_{2}\right), 3209$ $(\mathrm{NH}), 1638(\mathrm{C}=\mathrm{O}), 1607(\mathrm{C}=\mathrm{N}), 1146,1309\left(\mathrm{SO}_{2}\right) .{ }^{1} \mathrm{H}-\mathrm{NMR}\left(\mathrm{CDCl}_{3}+\right.$ DMSO- $\left.d_{6}\right) \delta: 1.90-2.00\left(\mathrm{~m}, 2 \mathrm{H}, \mathrm{C}_{1}^{\prime}-\mathrm{H}\right), 2.13-2.23\left(\mathrm{~m}, 2 \mathrm{H}, \mathrm{C}_{1}^{\prime}-\mathrm{H}\right), 2.83-$ $3.04\left(\mathrm{~m}, 4 \mathrm{H}, \mathrm{C}_{2}^{\prime}-\mathrm{H}\right), 5.91\left(\mathrm{bs}, 2 \mathrm{H}, \mathrm{NH}_{2}\right), 7.57-7.85(\mathrm{~m}, 10 \mathrm{H}, \mathrm{Ar}-\mathrm{H}), 9.96$ (bs, $1 \mathrm{H}, \mathrm{NH}) ;{ }^{13} \mathrm{C}-\mathrm{NMR}\left(\mathrm{CDCl}_{3}+\mathrm{DMSO}-d_{6}\right) \delta: 25.3\left(\mathrm{C}-1^{\prime}\right), 49.3(\mathrm{C}-4)$, 50.0 (C-2'), 158.1 (C-5), 171.9 (C-3), 126.7, 128.3, 132.8, 137.5; MS m/z: $435\left(\mathrm{M}^{+}\right)$. Anal. Calcd for $\mathrm{C}_{19} \mathrm{H}_{21} \mathrm{~N}_{3} \mathrm{O}_{5} \mathrm{~S}_{2}: \mathrm{C}, 52.40 ; \mathrm{H}, 4.86 ; \mathrm{N}, 9.65$; Found C, $52.52 ; \mathrm{H}, 4.82 ; \mathrm{N}, 9.75$.

5-Amino-4-(2'-phenylsulfonyl-1'-phenylethyl)-pyrazol-3-one (9a): White crystals, yield $80 \%$, mp $201-202^{\circ} \mathrm{C}$; IR $(\mathrm{KBr}) \mathrm{cm}^{-1}: 3475,3369\left(\mathrm{NH}_{2}\right)$, $3209(\mathrm{NH}), 1639(\mathrm{C}=\mathrm{O}), 1607(\mathrm{C}=\mathrm{N}), 1309,1146\left(\mathrm{SO}_{2}\right) .{ }^{1} \mathrm{H}-\mathrm{NMR}$ $\left(\mathrm{CDCl}_{3}+\mathrm{DMSO}-d_{6}\right) \delta: 3.07\left(\mathrm{dd}, 1 \mathrm{H}, \mathrm{C}_{2}^{\prime}-\mathrm{H}, J=4.3,14.1 \mathrm{~Hz}\right), 3.70(\mathrm{dd}, 1 \mathrm{H}$, $\left.\mathrm{C}_{2}^{\prime}-\mathrm{H}, J=9.4,14.0 \mathrm{~Hz}\right), 4.22-4.27\left(\mathrm{~m}, 1 \mathrm{H}, \mathrm{C}_{1}^{\prime}-\mathrm{H}\right), 4.33\left(\mathrm{~d}, 1 \mathrm{H}, \mathrm{C}_{4}-\mathrm{H}\right.$, $J=5.1 \mathrm{~Hz}), 5.82\left(\mathrm{bs}, 2 \mathrm{H}, \mathrm{NH}_{2}\right), 7.11-7.84(\mathrm{~m}, 10 \mathrm{H}, \mathrm{Ar}-\mathrm{H}), 9.89(\mathrm{bs}, 1 \mathrm{H}$, $\mathrm{NH}) ;{ }^{13} \mathrm{C}-\mathrm{NMR}\left(\mathrm{CDCl}_{3}+\mathrm{DMSO}-d_{6}\right) \delta: 52.3\left(\mathrm{C}-2^{\prime}\right), 54.6\left(\mathrm{C}-1^{\prime}\right), 61.8(\mathrm{C}-4)$ 157.1 (C-5), 174.7 (C-3), 125.9, 126.4, 127.2, 128.9, 129.7, 131.2, 136.8, 138.8; MS m/z: $343\left(\mathrm{M}^{+*}\right)$. Anal. Calcd for $\mathrm{C}_{17} \mathrm{H}_{17} \mathrm{~N}_{3} \mathrm{O}_{3} \mathrm{~S}$ : C, 59.46; H, 4.99; $\mathrm{N}, 12.24$; Found C, $59.55 ; \mathrm{H}, 4.95 ; \mathrm{N}, 12.18$.

5-Amino-4-[2'-phenylsulfonyl-1'-(4-chlorophenyl)ethyl]-pyrazol-3-one (9b): White solid, yield $86 \%, \mathrm{mp} 212-214^{\circ} \mathrm{C}$; IR $(\mathrm{KBr}) \mathrm{cm}^{-1}: 3355,3449$ $\left(\mathrm{NH}_{2}\right), 3200(\mathrm{NH}), 1626(\mathrm{C}=\mathrm{O}), 1614(\mathrm{C}=\mathrm{N}), 1315,1139\left(\mathrm{SO}_{2}\right) .{ }^{1} \mathrm{H}-\mathrm{NMR}$ $\left(\mathrm{CDCl}_{3}+\right.$ DMSO- $\left.d_{6}\right) \delta: 3.04\left(\mathrm{dd}, 1 \mathrm{H}, \mathrm{C}_{2}^{\prime}-\mathrm{H}, J=4.5,14.3 \mathrm{~Hz}\right), 3.72(\mathrm{dd}, 1 \mathrm{H}$, $\left.\mathrm{C}_{2}^{\prime}-\mathrm{H}, J=9.5,14.1 \mathrm{~Hz}\right), 4.23-4.29\left(\mathrm{~m}, 1 \mathrm{H}, \mathrm{C}_{1}^{\prime}-\mathrm{H}\right), 4.35\left(\mathrm{~d}, 1 \mathrm{H}, \mathrm{C}_{4}-\mathrm{H}\right.$, $J=5.2 \mathrm{~Hz}), 5.87\left(\mathrm{bs}, 2 \mathrm{H}, \mathrm{NH}_{2}\right), 7.14-7.99(\mathrm{~m}, 9 \mathrm{H}, \mathrm{Ar}-\mathrm{H}), 9.78(\mathrm{bs}, 1 \mathrm{H}$, $\mathrm{NH}) ;{ }^{13} \mathrm{C}-\mathrm{NMR}\left(\mathrm{CDCl}_{3}\right) \delta: 53.1\left(\mathrm{C}-2^{\prime}\right), 54.8\left(\mathrm{C}-1^{\prime}\right), 62.7(\mathrm{C}-4), 156.7(\mathrm{C}-$ 5), 175.0 (C-3), 126.3, 127.1, 127.6, 128.5, 129.2, 133.2, 137.4, 138.5; MS $m / z$ : $377\left(\mathrm{M}^{+}\right)$. Anal. Calcd for $\mathrm{C}_{17} \mathrm{H}_{16} \mathrm{ClN}_{3} \mathrm{O}_{3} \mathrm{~S}: \mathrm{C}, 54.04 ; \mathrm{H}, 4.27 ; \mathrm{N}$, 11.12; Found C, 53.97; H, 4.24; N, 11.08 .

5-Amino-4-[2'-(4-chlorophenylmethylsulfonyl)-1'-phenylethyl]-pyrazol3-one (10a): White crystals; yield $78 \%, \mathrm{mp} 206-208^{\circ} \mathrm{C}$; IR $(\mathrm{KBr}) \mathrm{cm}^{-1}$ : 3364, $3471\left(\mathrm{NH}_{2}\right), 3204(\mathrm{NH}), 1635(\mathrm{C}=\mathrm{O}), 1603(\mathrm{C}=\mathrm{N}), 1313,1142$ $\left(\mathrm{SO}_{2}\right) .{ }^{1} \mathrm{H}-\mathrm{NMR}\left(\mathrm{CDCl}_{3}+\mathrm{DMSO}-d_{6}\right) \quad \delta: 3.03\left(\mathrm{dd}, 1 \mathrm{H}, \mathrm{C}_{2}^{\prime}-\mathrm{H}, \quad J=4.1\right.$,
$14.0 \mathrm{~Hz}), 3.76\left(\mathrm{dd}, 1 \mathrm{H}, \mathrm{C}_{2}^{\prime}-\mathrm{H}, J=9.2,13.8 \mathrm{~Hz}\right), 4.18-4.25\left(\mathrm{~m}, 1 \mathrm{H}, \mathrm{C}_{1}^{\prime}-\mathrm{H}\right)$, 4.31 (s, $\left.2 \mathrm{H}, \mathrm{Ar}-\mathrm{CH}_{2}\right), 4.33$ (d, $1 \mathrm{H}, \mathrm{C}_{4}-\mathrm{H}, J=5.4 \mathrm{~Hz}$ ), 5.91 (bs, $2 \mathrm{H}, \mathrm{NH}_{2}$ ), $7.19-7.32(\mathrm{~m}, 9 \mathrm{H}, \mathrm{Ar}-\mathrm{H}), 9.84(\mathrm{bs}, 1 \mathrm{H}, \mathrm{NH}) ;{ }^{13} \mathrm{C}-\mathrm{NMR}\left(\mathrm{CDCl}_{3}+\mathrm{DMSO}-\right.$ $\left.d_{6}\right) \delta: 53.3\left(\mathrm{C}-2^{\prime}\right), 53.9\left(\mathrm{C}-1^{\prime}\right), 58.2\left(\mathrm{Ar}^{-} \mathrm{CH}_{2}\right), 62.4(\mathrm{C}-4), 154.2(\mathrm{C}-5)$, 175.3 (C-3), 127.4, 128.1, 128.9, 129.5, 131.2, 131.3, 139.7; MS m/z: 391 $\left(\mathrm{M}^{+*}\right)$. Anal. Calcd for $\mathrm{C}_{18} \mathrm{H}_{18} \mathrm{ClN}_{3} \mathrm{O}_{3} \mathrm{~S}: \mathrm{C}, 55.17 ; \mathrm{H}, 4.63 ; \mathrm{N}, 10.72$; Found C, $55.11 ; \mathrm{H}, 4.65 ; \mathrm{N}, 10.80$

5-Amino-4-[2'-(4-chlorophenylmethanesulfonyl)-1' -(4-chlorophenyl)ethyl]-pyrazol-3-one (10b): Light yellow solid; yield $82 \%, \mathrm{mp} 216-218^{\circ} \mathrm{C}$; IR $(\mathrm{KBr}) \mathrm{cm}^{-1}:$ 3358, $3446\left(\mathrm{NH}_{2}\right), 3208(\mathrm{NH}), 1633(\mathrm{C}=\mathrm{O}), 1620(\mathrm{C}=\mathrm{N})$, 1327, 1133, $\left(\mathrm{SO}_{2}\right) .{ }^{1} \mathrm{H}-\mathrm{NMR}\left(\mathrm{CDCl}_{3}+\mathrm{DMSO}-d_{6}\right) \delta: 3.07\left(\mathrm{dd}, 1 \mathrm{H}, \mathrm{C}_{2}^{\prime}-\mathrm{H}\right.$ $J=4.2,14.2 \mathrm{~Hz}), 3.79\left(\mathrm{dd}, 1 \mathrm{H}, \mathrm{C}_{2}^{\prime}-\mathrm{H}, J=9.3,13.9 \mathrm{~Hz}\right), 4.21-4.26(\mathrm{~m}, 1 \mathrm{H}$, $\left.\mathrm{C}_{1}^{\prime}-\mathrm{H}\right), 4.28\left(\mathrm{~s}, 2 \mathrm{H}, \mathrm{Ar}-\mathrm{CH}_{2}\right), 4.34\left(\mathrm{~d}, 1 \mathrm{H}, \mathrm{C}_{4}-\mathrm{H}, J=5.3 \mathrm{~Hz}\right), 5.84(\mathrm{bs}, 2 \mathrm{H}$ $\left.\mathrm{NH}_{2}\right), \quad 7.07-7.33$ (m, 8H, Ar-H), 9.87 (bs, $\left.1 \mathrm{H}, \quad \mathrm{NH}\right) ;{ }^{13} \mathrm{C}-\mathrm{NMR}$ $\left(\mathrm{CDCl}_{3}+\mathrm{DMSO}_{6}\right) \delta: 54.1\left(\mathrm{C}-2^{\prime}\right), 56.4\left(\mathrm{C}-1^{\prime}\right), 58.9\left(\mathrm{Ar}_{6}-\mathrm{CH}_{2}\right), 63.6(\mathrm{C}-4)$ 155.8 (C-5), 176.2 (C-3), 125.4, 126.4, 128.1, 129.5, 130.7, 132.1, 133.7, 139.2; MS m/z: $425\left(\mathrm{M}^{+}\right)$. Anal. Calcd for $\mathrm{C}_{18} \mathrm{H}_{17} \mathrm{Cl}_{2} \mathrm{~N}_{3} \mathrm{O}_{3} \mathrm{~S}: \mathrm{C}, 50.71 ; \mathrm{H}$, 4.02; N, 9.86; Found C, 50.80; H, 4.06; N, 9.82.

General Procedure of Synthesis of 3-Amino-4,4-bis-(2'-benzenesulfonylethyl)-isoxazol-5-one (3)/3-Amino-4-(2'-arylsulfonyl-1'-arylethyl)isoxazol-5-one $(11 \mathrm{a}-\mathrm{b}) / 3$-Amino-4-(2'-arylmethylsulfonyl-1' ${ }^{\prime}$-arylethyl)isoxazol-5-one $(\mathbf{1 2 a}-\mathbf{b}) \quad$ To a solution of $\mathbf{1 / 7 / 8}(0.01 \mathrm{~mol})$ in EtOH $(20 \mathrm{ml})$, hydroxylamine hydrochloride $(0.01 \mathrm{~mol})$ and piperidine $(5 \mathrm{ml})$ were added and refluxed for $4-5 \mathrm{~h}$. The solution was cooled and poured onto crushed ice, acidified with conc. $\mathrm{HCl}$. The reaction mixture was extracted with ethyl acetate. The organic layer was washed with brine, dried over anhydrous $\mathrm{Na}_{2} \mathrm{SO}_{4}$. Removal of the solvent under reduced pressure gave crude product which was purified by recrystallization from $\mathrm{MeOH}$.

3-Amino-4,4-bis-(2'-phenylsulfonylethyl)-isoxazol-5-one (3): White solid, yield $65 \%$, mp $178-180^{\circ} \mathrm{C}$; IR $(\mathrm{KBr}) \mathrm{cm}^{-1}: 3467,3356\left(\mathrm{NH}_{2}\right), 1646$ $(\mathrm{C}=\mathrm{O}), 1610(\mathrm{C}=\mathrm{N}), 1322,1139\left(\mathrm{SO}_{2}\right) .{ }^{1} \mathrm{H}-\mathrm{NMR}\left(\mathrm{CDCl}_{3}+\mathrm{DMSO}-d_{6}\right) \delta$ : $1.85-1.98\left(\mathrm{~m}, 2 \mathrm{H}, \mathrm{C}_{1}^{\prime}-\mathrm{H}\right), 2.16-2.21\left(\mathrm{~m}, 2 \mathrm{H}, \mathrm{C}_{1}^{\prime}-\mathrm{H}\right), 2.87-3.05(\mathrm{~m}, 4 \mathrm{H}$, $\left.\mathrm{C}_{2}^{\prime}-\mathrm{H}\right), \quad 5.86\left(\mathrm{bs}, 2 \mathrm{H}, \quad \mathrm{NH}_{2}\right), 7.41-7.98(\mathrm{~m}, 10 \mathrm{H}, \quad \mathrm{Ar}-\mathrm{H}) ;{ }^{13} \mathrm{C}-\mathrm{NMR}$ $\left(\mathrm{CDCl}_{3}+\mathrm{DMSO}-d_{6}\right) \delta: 24.3\left(\mathrm{C}-1^{\prime}\right), 46.7(\mathrm{C}-4), 50.3\left(\mathrm{C}-2^{\prime}\right), 156.9(\mathrm{C}-3)$, 174.6 (C-5), 125.7, 129.5, 131.2, 138.5; MS m/z: $436\left(\mathrm{M}^{+*}\right)$. Anal. Calcd for $\mathrm{C}_{19} \mathrm{H}_{20} \mathrm{~N}_{2} \mathrm{O}_{6} \mathrm{~S}_{2}$ : C, 52.28; H, 4.62; N, 6.42; Found C, 52.43; H, 4.64; N, 6.53.

3-Amino-4-(2'-phenylsulfonyl-1' -phenylethyl)-isoxazol-5-one (11a): White crystals, yield $68 \%$, mp $184-186^{\circ} \mathrm{C}$; IR $(\mathrm{KBr}) \mathrm{cm}^{-1}: 3435,3349$ $\left(\mathrm{NH}_{2}\right), 1636(\mathrm{C}=\mathrm{O}), 1612(\mathrm{C}=\mathrm{N}), 1333,1135\left(\mathrm{SO}_{2}\right) .{ }^{1} \mathrm{H}-\mathrm{NMR}\left(\mathrm{DMSO}-d_{6}\right)$ $\delta$ : $3.05\left(\mathrm{dd}, 1 \mathrm{H}, \mathrm{C}_{2}^{\prime}-\mathrm{H}, J=4.3,14.1 \mathrm{~Hz}\right), 3.68\left(\mathrm{dd}, 1 \mathrm{H}, \mathrm{C}_{2}^{\prime}-\mathrm{H}, J=9.5\right.$, $14.0 \mathrm{~Hz}), 4.24-4.28\left(\mathrm{~m}, 1 \mathrm{H}, \mathrm{C}_{1}^{\prime}-\mathrm{H}\right), 4.37\left(\mathrm{~d}, 1 \mathrm{H}, \mathrm{C}_{4}-\mathrm{H}, J=5.0 \mathrm{~Hz}\right), 5.77(\mathrm{bs}$, $\left.2 \mathrm{H}, \mathrm{NH}_{2}\right), 7.08-7.85(\mathrm{~m}, 10 \mathrm{H}, \mathrm{Ar}-\mathrm{H}) ;{ }^{13} \mathrm{C}-\mathrm{NMR}\left(\mathrm{CDCl}_{3}+\mathrm{DMSO}_{6}\right) \delta$ : $54.5\left(\mathrm{C}-2^{\prime}\right), 56.2\left(\mathrm{C}-1^{\prime}\right), 63.3$ (C-4), 159.2 (C-3), $175.4(\mathrm{C}-5), 124.2,125.3$, 126.7, 127.5, 129.1, 131.4, 137.2, 138.3; MS m/z: $344\left(\mathrm{M}^{+*}\right)$. Anal. Calcd for $\mathrm{C}_{17} \mathrm{H}_{16} \mathrm{~N}_{2} \mathrm{O}_{4} \mathrm{~S}$ : C, 59.29; H, 4.68; N, 8.13; Found C, 59.39; H, 4.65; N, 8.05 .

3-Amino-4-[2'-phenylsulfonyl-1' -(4-chlorophenyl)ethyl]-isoxazol-5-one (11b): White solid, yield $73 \%$, mp $189-191{ }^{\circ} \mathrm{C}$; IR $(\mathrm{KBr}) \mathrm{cm}^{-1}: 3441,3352$ $\left(\mathrm{NH}_{2}\right), 1621(\mathrm{C}=\mathrm{O}), 1619(\mathrm{C}=\mathrm{N}), 1337,1141\left(\mathrm{SO}_{2}\right) .{ }^{1} \mathrm{H}-\mathrm{NMR}\left(\mathrm{DMSO}-d_{6}\right)$ $\delta: 3.04\left(\mathrm{dd}, 1 \mathrm{H}, \mathrm{C}_{2}^{\prime}-\mathrm{H}, J=4.4,14.2 \mathrm{~Hz}\right), 3.68\left(\mathrm{dd}, 2 \mathrm{H}, \mathrm{C}_{2}^{\prime}-\mathrm{H}, J=9.6\right.$, $14.2 \mathrm{~Hz}), 4.08-4.19\left(\mathrm{~m}, 1 \mathrm{H}, \mathrm{C}_{1}^{\prime}-\mathrm{H}\right), 4.44\left(\mathrm{~d}, 1 \mathrm{H}, \mathrm{C}_{4}-\mathrm{H}, J=5.2 \mathrm{~Hz}\right), 5.87(\mathrm{bs}$, $\left.2 \mathrm{H}, \mathrm{NH}_{2}\right), 7.18-7.39$ (m, 9H, Ar-H); ${ }^{13} \mathrm{C}-\mathrm{NMR}\left(\mathrm{CDCl}_{3}+\mathrm{DMSO}-d_{6}\right) \delta$ : $53.5\left(\mathrm{C}-2^{\prime}\right), 58.7\left(\mathrm{C}-1^{\prime}\right), 64.8$ (C-4), 158.3 (C-3), 176.2 (C-5), 127.3, 127.4, 127.5, 128.2, 128.7, 136.7, 140.3, 142.7: MS m/z: $378\left(\mathrm{M}^{+}\right)$. Anal. Calcd for $\mathrm{C}_{17} \mathrm{H}_{15} \mathrm{ClN}_{2} \mathrm{O}_{4} \mathrm{~S}: \mathrm{C}, 53.90 ; \mathrm{H}, 3.99 ; \mathrm{N}, 7.39$; Found $\mathrm{C}, 54.01 ; \mathrm{H}, 4.04 ; \mathrm{N}$, 7.46 .

3-Amino-4-[2' -(4-chlorophenylmethylsulfonyl)-1'-phenylethyl]-isoxazol5-one (12a): Light yellow solid, yield $67 \%, \mathrm{mp} 195-197^{\circ} \mathrm{C}$; IR (KBr) $\mathrm{cm}^{-1}: 3444,3359\left(\mathrm{NH}_{2}\right), 1642(\mathrm{C}=\mathrm{O}), 1603(\mathrm{C}=\mathrm{N}), 1331,1128\left(\mathrm{SO}_{2}\right) .{ }^{1} \mathrm{H}-$ NMR (DMSO- $d_{6}$ ) $\delta: 3.08$ (dd, $\left.1 \mathrm{H}, \mathrm{C}_{2}^{\prime}-\mathrm{H}, J=4.5,14.4 \mathrm{~Hz}\right), 3.74\left(\mathrm{dd}, 1 \mathrm{H}, \mathrm{C}_{2}^{\prime}-\right.$ $\mathrm{H}, J=9.7,14.3 \mathrm{~Hz}), 4.21-4.27\left(\mathrm{~m}, 1 \mathrm{H}, \mathrm{C}_{1}^{\prime}-\mathrm{H}\right), 4.29\left(\mathrm{~d}, 1 \mathrm{H}, \mathrm{C}_{4}-\mathrm{H}\right.$, $J=5.1 \mathrm{~Hz}), 4.34\left(\mathrm{~s}, 2 \mathrm{H}, \mathrm{Ar}-\mathrm{CH}_{2}\right), 5.88\left(\mathrm{bs}, 2 \mathrm{H}, \mathrm{NH}_{2}\right), 7.02-7.63(\mathrm{~m}, 9 \mathrm{H}$ $\mathrm{Ar}-\mathrm{H}) ;{ }^{13} \mathrm{C}-\mathrm{NMR}\left(\mathrm{CDCl}_{3}+\mathrm{DMSO}-d_{6}\right) \delta: 54.2\left(\mathrm{C}-2^{\prime}\right), 57.8\left(\mathrm{C}-1^{\prime}\right), 58.8(\mathrm{Ar}-$ $\left.\mathrm{CH}_{2}\right), 62.9$ (C-4), 158.3 (C-3), 173.7 (C-5), 126.3, 127.5, 128.7, 129.4, 129.9, 131.8, 139.2; MS m/z: $392\left(\mathrm{M}^{+\cdot}\right)$. Anal. Calcd for $\mathrm{C}_{18} \mathrm{H}_{17} \mathrm{ClN}_{2} \mathrm{O}_{4} \mathrm{~S}: \mathrm{C}$, 55.03; H, 4.36; N, 7.13; Found C, 55.15; H, 4.32; N, 7.09.

3-Amino-4-[2'-(4-chlorophenylmethylsulfonyl)-1' -(4-chlorophenyl)ethyl]-isoxazol-5-one (12b): Colourless crystals, yield 70\%, mp 200 $202^{\circ} \mathrm{C}$; IR $(\mathrm{KBr}) \mathrm{cm}^{-1}: 3453,3343\left(\mathrm{NH}_{2}\right), 1631(\mathrm{C}=\mathrm{O}), 1606(\mathrm{C}=\mathrm{N})$, 1338, $1145\left(\mathrm{SO}_{2}\right) .{ }^{1} \mathrm{H}-\mathrm{NMR}$ (DMSO- $\left.d_{6}\right) \delta: 3.03\left(\mathrm{dd}, 1 \mathrm{H}, \mathrm{C}_{2}^{\prime}-\mathrm{H}, J=4.6\right.$, $14.5 \mathrm{~Hz}), 3.71\left(\mathrm{dd}, 1 \mathrm{H}, \mathrm{C}_{2}^{\prime}-\mathrm{H}, J=9.8,14.4 \mathrm{~Hz}\right), 4.19-4.25\left(\mathrm{~m}, 1 \mathrm{H}, \mathrm{C}_{1}^{\prime}-\mathrm{H}\right)$, $4.31\left(\mathrm{~d}, 1 \mathrm{H}, \mathrm{C}_{4}-\mathrm{H}, J=5.3 \mathrm{~Hz}\right), 4.35\left(\mathrm{~s}, 2 \mathrm{H}, \mathrm{Ar}-\mathrm{CH}_{2}\right), 5.91\left(\mathrm{bs}, 2 \mathrm{H}, \mathrm{NH}_{2}\right)$ $7.03-7.45(\mathrm{~m}, 8 \mathrm{H}, \mathrm{Ar}-\mathrm{H}) ;{ }^{13} \mathrm{C}-\mathrm{NMR}$ (DMSO- $\left.d_{6}\right) \delta: 53.8\left(\mathrm{C}-2^{\prime}\right), 54.9(\mathrm{C}-$ $\left.1^{\prime}\right), 57.7\left(\mathrm{Ar}^{-} \mathrm{CH}_{2}\right), 62.4(\mathrm{C}-4), 159.1(\mathrm{C}-3), 174.2(\mathrm{C}-5), 125.2,126.4$, 
127.3, 129.5, 131.8, 131.9, 133.5, 140.3; MS m/z: $426\left(\mathrm{M}^{+*}\right)$. Anal. Calcd for $\mathrm{C}_{18} \mathrm{H}_{16} \mathrm{Cl}_{2} \mathrm{~N}_{2} \mathrm{O}_{4} \mathrm{~S}$ : C, 50.59; H, 3.77; N, 6.56; Found C, 50.50; H, 3.75; N, 6.60 .

General Procedure of Synthesis of 6-Amino-5,5-bis-(2'-phenylsulfonylethyl)-2-hydroxypyrimidine-4-one (4)/6-Amino-5-(2'-arylsulfonyl1 '-arylethyl)-2-hydroxypyrimidine-4-one $\quad(13 a-b) / 6-A m i n o-5-(2 '$-arylmethylsulfonyl-1' -arylethyl)-2-hydroxypyrimidine-4-one (14a-b) The compound 1/7/8 $(0.01 \mathrm{~mol})$ was dissolved in EtOH $(10 \mathrm{ml})$. To this urea $(0.01 \mathrm{~mol})$ in EtOH $(10 \mathrm{ml})$ and piperidine $(5 \mathrm{ml})$ were added and refluxed for $6-9 \mathrm{~h}$. The contents were cooled, poured onto crushed ice containing conc. $\mathrm{HCl}$ and extracted with ethylacetate. The organic layer was washed with brine and dried over anhydrous $\mathrm{Na}_{2} \mathrm{SO}_{4}$. Removal of the solvent in vacuo gave crude product which was purified by recrystallization from $\mathrm{MeOH}$.

6-Amino-5,5-bis-(2' -phenylsulfonylethyl)-2-hydroxypyrimidine-4-one (4): White needles, yield $66 \%$, mp $270-272{ }^{\circ} \mathrm{C}$; IR (KBr) $\mathrm{cm}^{-1}$ : 3458 , $3362\left(\mathrm{NH}_{2}\right), 3335(\mathrm{OH}), 1635(\mathrm{C}=\mathrm{O}), 1604(\mathrm{C}=\mathrm{N}), 1335,1145\left(\mathrm{SO}_{2}\right) .{ }^{1} \mathrm{H}-$ NMR $\left(\mathrm{CDCl}_{3}+\mathrm{DMSO}-d_{6}\right) \delta: 1.92-2.01\left(\mathrm{~m}, 2 \mathrm{H}, \mathrm{C}_{1}^{\prime}-\mathrm{H}\right), 2.15-2.22(\mathrm{~m}$, $\left.2 \mathrm{H}, \mathrm{C}_{1}^{\prime}-\mathrm{H}\right), 2.85-3.01\left(\mathrm{~m}, 4 \mathrm{H}, \mathrm{C}_{2}^{\prime}-\mathrm{H}\right), 5.94\left(\mathrm{bs}, 2 \mathrm{H}, \mathrm{NH}_{2}\right), 6.84(\mathrm{~s}, 1 \mathrm{H}$ $\mathrm{OH}), 7.42-7.85(\mathrm{~m}, 10 \mathrm{H}, \mathrm{Ar}-\mathrm{H}) ;{ }^{13} \mathrm{C}-\mathrm{NMR}\left(\mathrm{CDCl}_{3}+\mathrm{DMSO}-d_{6}\right) \delta: 24.7$ $\left(\mathrm{C}-1^{\prime}\right), 47.2$ (C-5), 49.1 (C-2' ), 157.4 (C-6), 161.2 (C-2), 178.7 (C-4), 125.8, 127.3, 131.6, 136.2; MS m/z: $463\left(\mathrm{M}^{+\cdot}\right)$. Anal. Calcd for $\mathrm{C}_{20} \mathrm{H}_{21} \mathrm{~N}_{3} \mathrm{O}_{6} \mathrm{~S}_{2}: \mathrm{C}$, 51.82; H, 4.57; N, 9.07. Found C, 51.70; H, 4.60; N, 9.14.

6-Amino-5-(2'-phenylsulfonyl-1' -phenylethyl)-2-hydroxypyrimidine-4one (13a): Colourless crystals, yield $66 \%, \mathrm{mp} 284-286^{\circ} \mathrm{C}$; IR $(\mathrm{KBr}) \mathrm{cm}^{-1}$ 3442, $3365\left(\mathrm{NH}_{2}\right), 3328(\mathrm{OH}), 1635(\mathrm{C}=\mathrm{O}), 1609(\mathrm{C}=\mathrm{N}), 1334,1142$ $\left(\mathrm{SO}_{2}\right) .{ }^{1} \mathrm{H}-\mathrm{NMR}\left(\mathrm{CDCl}_{3}+\mathrm{DMSO}-d_{6}\right) \quad \delta: 3.11\left(\mathrm{dd}, 1 \mathrm{H}, \mathrm{C}_{2}^{\prime}-\mathrm{H}, J=4.4\right.$, $14.3 \mathrm{~Hz}), 3.79\left(\mathrm{dd}, 1 \mathrm{H}, \mathrm{C}_{2}^{\prime}-\mathrm{H}, J=9.4,14.4 \mathrm{~Hz}\right), 4.17-4.22\left(\mathrm{~m}, 1 \mathrm{H}, \mathrm{C}_{1}^{\prime}-\mathrm{H}\right)$, $4.33\left(\mathrm{~d}, 1 \mathrm{H}, \mathrm{C}_{5}-\mathrm{H}, J=5.4 \mathrm{~Hz}\right), 5.86\left(\mathrm{bs}, 2 \mathrm{H}, \mathrm{NH}_{2}\right), 6.92(\mathrm{bs}, 1 \mathrm{H}, \mathrm{OH}), 7.11-$ $7.82(\mathrm{~m}, 10 \mathrm{H}, \mathrm{Ar}-\mathrm{H}) ;{ }^{13} \mathrm{C}-\mathrm{NMR}\left(\mathrm{CDCl}_{3}+\mathrm{DMSO}_{-}\right) \delta: 52.7\left(\mathrm{C}-2^{\prime}\right), 53.6$ $\left(\mathrm{C}-1^{\prime}\right), 63.9$ (C-5), 158.8 (C-6), 162.5 (C-2), 176.3 (C-4), 125.3, 125.9, 126.7, 127.4, 129.1, 131.3, 137.8, 138.3; MS m/z: $371\left(\mathrm{M}^{+*}\right)$. Anal. Calcd for $\mathrm{C}_{18} \mathrm{H}_{17} \mathrm{~N}_{3} \mathrm{O}_{4} \mathrm{~S}$ : C, 58.21; H, 4.61; N, 11.31; Found C, 58.30; H, 4.66; N, 11.41 .

6-Amino-5-[2'-(4-chlorophenylsulfonyl)-1' -phenylethyl]-2-hydroxypyrimidine-4-one (13b): White solid, yield $68 \%, \mathrm{mp} 268-270{ }^{\circ} \mathrm{C}$; IR $(\mathrm{KBr})$ $\mathrm{cm}^{-1}$ : 3379, $3453\left(\mathrm{NH}_{2}\right), 3315(\mathrm{OH}), 1625(\mathrm{C}=\mathrm{O}), 1612(\mathrm{C}=\mathrm{N}), 1328$, $1130\left(\mathrm{SO}_{2}\right) .{ }^{1} \mathrm{H}-\mathrm{NMR}\left(\mathrm{CDCl}_{3}+\mathrm{DMSO}-d_{6}\right) \delta: 3.07\left(\mathrm{dd}, 1 \mathrm{H}, \mathrm{C}_{2}^{\prime}-\mathrm{H}, J=4.5\right.$, $14.4 \mathrm{~Hz}), 3.74\left(\mathrm{dd}, 1 \mathrm{H}, \mathrm{C}_{2}^{\prime}-\mathrm{H}, J=9.5,14.5 \mathrm{~Hz}\right), 4.21-4.26\left(\mathrm{~m}, 1 \mathrm{H}, \mathrm{C}_{1}^{\prime}-\mathrm{H}\right)$, $4.31\left(\mathrm{~d}, 1 \mathrm{H}, \mathrm{C}_{5}-\mathrm{H}, J=5.4 \mathrm{~Hz}\right), 5.89\left(\mathrm{bs}, 2 \mathrm{H}, \mathrm{NH}_{2}\right), 6.87$ (bs, $\left.1 \mathrm{H}, \mathrm{OH}\right), 7.04$ $7.87(\mathrm{~m}, 9 \mathrm{H}, \mathrm{Ar}-\mathrm{H}) ;{ }^{13} \mathrm{C}-\mathrm{NMR}\left(\mathrm{CDCl}_{3}+\mathrm{DMSO}-d_{6}\right) \delta: 52.1\left(\mathrm{C}-2^{\prime}\right), 54.9(\mathrm{C}-$ $1^{\prime}$ ), 64.5 (C-5), 159.2 (C-6), 163.4 (C-2), 175.7 (C-4), 125.1, 126.9, 128.1, 129.4, 130.4, 131.8, 137.9, 140.1; MS m/z: $405\left(\mathrm{M}^{+*}\right)$. Anal. Calcd for $\mathrm{C}_{18} \mathrm{H}_{16} \mathrm{ClN}_{3} \mathrm{O}_{4} \mathrm{~S}$ : C, 53.27; H, 3.97; N, 10.35.;Found C, 53.22; H, 4.00; N, 10.30 .

6-Amino-5-[2'-(4-chlorophenylmethylsulfonyl)-1'-phenylethyl]-2-hydroxypyrimidine-4-one (14a): White crystals, yield $70 \%$, mp $262-264^{\circ} \mathrm{C}$; IR $(\mathrm{KBr}) \mathrm{cm}^{-1}: 3360,3445\left(\mathrm{NH}_{2}\right), 3331(\mathrm{OH}), 1637(\mathrm{C}=\mathrm{O}), 1601(\mathrm{C}=\mathrm{N})$, 1328, $1146\left(\mathrm{SO}_{2}\right) .{ }^{1} \mathrm{H}-\mathrm{NMR}\left(\mathrm{CDCl}_{3}+\mathrm{DMSO}-d_{6}\right) \delta: 3.05\left(\mathrm{dd}, 1 \mathrm{H}, \mathrm{C}_{2}^{\prime}-\mathrm{H}\right.$, $J=4.2,14.1 \mathrm{~Hz}), 3.67\left(\mathrm{dd}, 1 \mathrm{H}, \mathrm{C}_{2}^{\prime}-\mathrm{H}, J=9.2,14.1 \mathrm{~Hz}\right), 4.14-4.21(\mathrm{~m}, 1 \mathrm{H}$, $\left.\mathrm{C}_{1}^{\prime}-\mathrm{H}\right), 4.26\left(\mathrm{~s}, 2 \mathrm{H}, \mathrm{Ar}-\mathrm{CH}_{2}\right), 4.33\left(\mathrm{~d}, 1 \mathrm{H}, \mathrm{C}_{5}-\mathrm{H}, J=5.2 \mathrm{~Hz}\right), 5.78(\mathrm{bs}, 2 \mathrm{H}$, $\left.\mathrm{NH}_{2}\right), 6.93$ (bs, 1H, OH), 7.09-7.46 (m, 9H, Ar-H); ${ }^{13} \mathrm{C}-\mathrm{NMR}\left(\mathrm{CDCl}_{3}+\right.$ DMSO- $\left.d_{6}\right) \delta: 53.8\left(\mathrm{C}-2^{\prime}\right), 55.2\left(\mathrm{C}-1^{\prime}\right), 59.8\left(\mathrm{Ar}^{-} \mathrm{CH}_{2}\right), 63.3(\mathrm{C}-5), 158.7(\mathrm{C}-$ 6), 162.7 (C-2), 174.2 (C-4), 126.1, 126.9, 127.0, 127.7, 129.3, 131.3, 137.8, 140.4; MS m/z: $419\left(\mathrm{M}^{+*}\right)$. Anal. Calcd for $\mathrm{C}_{19} \mathrm{H}_{18} \mathrm{ClN}_{3} \mathrm{O}_{4} \mathrm{~S}: \mathrm{C}, 54.35 ; \mathrm{H}$, 4.32; N, 10.01; Found C, 54.44; H, 4.33; N, 10.08 .

6-Amino-5-[2'-(4-chlorophenylmethylsulfonyl)-1' -(4-chlorophenyl)ethyl]-2-hydroxypyrimidine-4-one (14b): White crystals, yield 69\%, mp $280-282^{\circ} \mathrm{C}$; IR $(\mathrm{KBr}) \mathrm{cm}^{-1}$ : $1134,1325\left(\mathrm{SO}_{2}\right), 1610(\mathrm{C}=\mathrm{N}), 1630$ $(\mathrm{C}=\mathrm{O}), 3324(\mathrm{OH}), 3372,3443\left(\mathrm{NH}_{2}\right) .{ }^{1} \mathrm{H}-\mathrm{NMR}\left(\mathrm{CDCl}_{3}+\mathrm{DMSO}-d_{6}\right) \delta$ 3.09 (dd, $\left.1 \mathrm{H}, \mathrm{C}_{2}^{\prime}-\mathrm{H}, J=4.3,14.2 \mathrm{~Hz}\right), 3.77$ (dd, $\left.1 \mathrm{H}, \mathrm{C}_{2}^{\prime}-\mathrm{H}, J=9.3,14.2 \mathrm{~Hz}\right)$, $4.19-4.24\left(\mathrm{~m}, 1 \mathrm{H}, \mathrm{C}_{1}^{\prime}-\mathrm{H}\right), 4.32\left(\mathrm{~d}, 1 \mathrm{H}, \mathrm{C}_{5}-\mathrm{H}, J=5.3 \mathrm{~Hz}\right), 4.25(\mathrm{~s}, 2 \mathrm{H}, \mathrm{Ar}-$ $\mathrm{CH}_{2}$ ), 5.86 (bs, 2H, NH $\left.\mathrm{NH}_{2}\right), 6.89$ (bs, $\left.1 \mathrm{H}, \mathrm{OH}\right), 7.04-7.39$ (m, 8H, Ar-H); ${ }^{13} \mathrm{C}-\mathrm{NMR}\left(\mathrm{CDCl}_{3}+\mathrm{DMSO}-d_{6}\right) \delta: 54.2\left(\mathrm{C}-2^{\prime}\right), 54.4\left(\mathrm{C}-1^{\prime}\right), 58.5\left(\mathrm{Ar}-\mathrm{CH}_{2}\right)$, 64.9 (C-5), 158.7 (C-6), 161.8 (C-2), 173.8 (C-4), 125.4, 126.1, 127.3, 128.7, 129.8, 131.7, 134.2, 138.1; MS $m / z$ : $453\left(\mathrm{M}^{+}\right)$. Anal. Calcd for $\mathrm{C}_{19} \mathrm{H}_{17} \mathrm{Cl}_{2} \mathrm{~N}_{3} \mathrm{O}_{4} \mathrm{~S}: \mathrm{C}, 50.23 ; \mathrm{H}, 3.77 ; \mathrm{N}, 9.25$; Found C, 50.29; H, 3.80; N, 9.20 .

General Procedure of Synthesis of 6-Imino-5,5-bis-(2'-phenylsulfonylethyl)-1,3-dimethylpyrimidine-2,4-dione (5)/6-Imino-5-(2'-arylsulfonyl-1'-arylethyl)-1,3-dimethylpyrimidine-2,4-dione $(15 a-b) / 6-I m i n o-$ 5-(2'-arylmethylsulfonyl-1' -arylethyl)-1,3-dimethylpyrimidine-2,4-dione (16a-b) A mixture of $\mathbf{1} / \mathbf{7} / \mathbf{8}(0.01 \mathrm{~mol}), 1,3$-dimethylurea $(0.01 \mathrm{~mol})$, EtOH $(15 \mathrm{ml})$ and piperidine $(5 \mathrm{ml})$ was taken and refluxed for $6-10 \mathrm{~h}$. The contents were diluted with ice-cold water, acidified with conc. $\mathrm{HCl}$ and extracted with ethyl acetate. The organic layer was washed with brine and dried over anhydrous $\mathrm{Na}_{2} \mathrm{SO}_{4}$. Removal of the solvent under vacuum afforded crude product which was purified by recrystallization from $\mathrm{MeOH}$.

6-Imino-5,5-bis-(2' -phenylsulfonylethyl)-1,3-dimethylpyrimidine-2,4dione (5): White powder, yield $64 \%, \mathrm{mp} 273-275^{\circ} \mathrm{C}$; IR $(\mathrm{KBr}) \mathrm{cm}^{-1}: 3215$ $(\mathrm{NH}), 1634(\mathrm{C}=\mathrm{O}), 1612(\mathrm{C}=\mathrm{N}), 1327,1133\left(\mathrm{SO}_{2}\right) .{ }^{1} \mathrm{H}-\mathrm{NMR}\left(\mathrm{CDCl}_{3}\right) \delta$ : $1.88-1.96\left(\mathrm{~m}, 2 \mathrm{H}, \mathrm{C}_{1}^{\prime}-\mathrm{H}\right), 2.11-2.20\left(\mathrm{~m}, 2 \mathrm{H}, \mathrm{C}_{1}^{\prime}-\mathrm{H}\right), 2.70\left(\mathrm{~s}, 6 \mathrm{H}, \mathrm{N}-\mathrm{CH}_{3}\right)$ $2.80-2.96\left(\mathrm{~m}, 4 \mathrm{H}, \mathrm{C}_{2}^{\prime}-\mathrm{H}\right), 7.44-7.87(\mathrm{~m}, 10 \mathrm{H}, \mathrm{Ar}-\mathrm{H}), 9.18(\mathrm{bs}, 1 \mathrm{H}, \mathrm{NH})$; ${ }^{13} \mathrm{C}-\mathrm{NMR}\left(\mathrm{CDCl}_{3}\right) \delta: 23.8\left(\mathrm{C}-1^{\prime}\right), 28.9\left(\mathrm{~N}-\mathrm{CH}_{3}\right), 29.2\left(\mathrm{~N}-\mathrm{CH}_{3}\right), 42.5(\mathrm{C}-5)$, $49.4\left(\mathrm{C}-2^{\prime}\right), 158.4$ (C-2), 164.2 (C-6), 178.0 (C-4), 126.6, 130.1, 132.5, 136.3; MS m/z: $491\left(\mathrm{M}^{+\cdot}\right)$. Anal. Calcd for $\mathrm{C}_{22} \mathrm{H}_{25} \mathrm{~N}_{3} \mathrm{O}_{6} \mathrm{~S}_{2}$ : C, 53.75; H, $5.13 ; \mathrm{N}, 8.55$; Found C, 53.89; H, 5.15; N, 8.67

6-Imino-5-(2' -phenylsulfonyl-1' -phenylethyl)-1,3-dimethylpyrimidine2,4-dione (15a): White solid, yield $64 \%, \mathrm{mp} 287-288^{\circ} \mathrm{C}$; IR $(\mathrm{KBr}) \mathrm{cm}^{-1}$ : $3212(\mathrm{NH}), 1641(\mathrm{C}=\mathrm{O}), 1603(\mathrm{C}=\mathrm{N}), 1326,1137\left(\mathrm{SO}_{2}\right) .{ }^{1} \mathrm{H}-\mathrm{NMR}$ $\left(\mathrm{CDCl}_{3}+\mathrm{DMSO}-d_{6}\right) \delta: 2.73\left(\mathrm{~s}, 6 \mathrm{H}, \mathrm{N}-\mathrm{CH}_{3}\right), 3.02\left(\mathrm{dd}, 1 \mathrm{H}, \mathrm{C}_{2}^{\prime}-\mathrm{H}, J=4.1\right.$, $14.0 \mathrm{~Hz}), 3.75\left(\mathrm{dd}, 1 \mathrm{H}, \mathrm{C}_{2}^{\prime}-\mathrm{H}, J=9.6,14.3 \mathrm{~Hz}\right), 4.15-4.21\left(\mathrm{~m}, 1 \mathrm{H}, \mathrm{C}_{1}^{\prime}-\mathrm{H}\right)$, $4.34\left(\mathrm{~d}, 1 \mathrm{H}, \mathrm{C}_{5}-\mathrm{H}, J=5.1 \mathrm{~Hz}\right), 7.05-7.87(\mathrm{~m}, 10 \mathrm{H}, \mathrm{Ar}-\mathrm{H}), 9.21$ (bs, $1 \mathrm{H}$, $\mathrm{NH}) ;{ }^{13} \mathrm{C}-\mathrm{NMR}\left(\mathrm{CDCl}_{3}+\mathrm{DMSO}-d_{6}\right) \delta: 27.9\left(\mathrm{~N}-\mathrm{CH}_{3}\right), 28.5\left(\mathrm{~N}-\mathrm{CH}_{3}\right), 52.8$ $\left(\mathrm{C}-2^{\prime}\right), 54.1\left(\mathrm{C}-1^{\prime}\right), 64.3$ (C-5), 159.7 (C-2), 163.2 (C-6), 176.5 (C-4), 125.5, 126.4, 126.8, 127.8, 129.5, 131.3, 138.5, 141.2; MS m/z: $399\left(\mathrm{M}^{+*}\right)$. Anal. Calcd for $\mathrm{C}_{20} \mathrm{H}_{21} \mathrm{~N}_{3} \mathrm{O}_{4} \mathrm{~S}$ : C, 60.13; H, 5.30; N, 10.52. Found C, 60.24; H, 5.28; N, 10.60.

6-Imino-5-[2'-phenylsulfonyl-1' -(4-chlorophenyl)ethyl]-1,3-dimethylpyrimidine-2,4-dione (15b): White solid, yield $67 \%, \mathrm{mp} 266-267^{\circ} \mathrm{C}$; IR $(\mathrm{KBr}) \mathrm{cm}^{-1}: 3217(\mathrm{NH}), 1634(\mathrm{C}=\mathrm{O}), 1607(\mathrm{C}=\mathrm{N}), 1313,1128\left(\mathrm{SO}_{2}\right) .{ }^{1} \mathrm{H}-$ NMR $\left(\mathrm{CDCl}_{3}+\mathrm{DMSO}_{6}\right) \delta: 2.71\left(\mathrm{~s}, 6 \mathrm{H}, \mathrm{N}-\mathrm{CH}_{3}\right), 3.06\left(\mathrm{dd}, 1 \mathrm{H}, \mathrm{C}_{2}^{\prime}-\mathrm{H}\right.$, $J=4.3,14.3 \mathrm{~Hz}), 3.78\left(\mathrm{dd}, 1 \mathrm{H}, \mathrm{C}_{2}^{\prime}-\mathrm{H}, J=9.7,14.4 \mathrm{~Hz}\right), 4.16-4.23(\mathrm{~m}, 1 \mathrm{H}$, $\left.\mathrm{C}_{1}^{\prime}-\mathrm{H}\right), 4.32\left(\mathrm{~d}, 1 \mathrm{H}, \mathrm{C}_{5}-\mathrm{H}, J=5.2 \mathrm{~Hz}\right), 7.01-7.88(\mathrm{~m}, 9 \mathrm{H}, \mathrm{Ar}-\mathrm{H}), 9.18$ (bs, $1 \mathrm{H}, \mathrm{NH}) ;{ }^{13} \mathrm{C}-\mathrm{NMR}\left(\mathrm{CDCl}_{3}+\mathrm{DMSO}-d_{6}\right) \delta: 28.4\left(\mathrm{~N}-\mathrm{CH}_{3}\right), 29.1\left(\mathrm{~N}-\mathrm{CH}_{3}\right)$, $53.2\left(\mathrm{C}-2^{\prime}\right), 54.7\left(\mathrm{C}-1^{\prime}\right), 65.2$ (C-5), 158.6 (C-2), 162.4 (C-6), 175.3 (C-4), $126.5,127.1,127.9,129.2,130.5,132.5,138.8,140.3 ; \mathrm{MS} m / z: 433\left(\mathrm{M}^{+\cdot}\right)$. Anal. Calcd for $\mathrm{C}_{20} \mathrm{H}_{20} \mathrm{ClN}_{3} \mathrm{O}_{4} \mathrm{~S}$ : C, 55.36; H, 4.65; N, 9.68; Found C, 55.30; $\mathrm{H}, 4.70 ; \mathrm{N}, 9.74$.

6-Imino-5-[2' -(4-chlorophenylmethylsulfonyl)-1' -phenylethyl]-1,3-dimethylpyrimidine-2,4-dione (16a): White solid, yield $62 \%, \mathrm{mp} 270$ $272{ }^{\circ} \mathrm{C}$; IR $(\mathrm{KBr}) \mathrm{cm}^{-1}: 3232(\mathrm{NH}), 1640(\mathrm{C}=\mathrm{O}), 1615(\mathrm{C}=\mathrm{N}), 1324,1125$ $\left(\mathrm{SO}_{2}\right) .{ }^{1} \mathrm{H}-\mathrm{NMR}\left(\mathrm{CDCl}_{3}+\mathrm{DMSO}-d_{6}\right) \delta: 2.74\left(\mathrm{~s}, 6 \mathrm{H}, \mathrm{N}-\mathrm{CH}_{3}\right), 3.08(\mathrm{dd}, 1 \mathrm{H}$, $\left.\mathrm{C}_{2}^{\prime}-\mathrm{H}, J=4.5,14.5 \mathrm{~Hz}\right), 3.71\left(\mathrm{dd}, 1 \mathrm{H}, \mathrm{C}_{2}^{\prime}-\mathrm{H}, J=9.5,14.6 \mathrm{~Hz}\right), 4.21-4.25$ $\left(\mathrm{m}, 1 \mathrm{H}, \mathrm{C}_{1}^{\prime}-\mathrm{H}\right), 4.28\left(\mathrm{~s}, 2 \mathrm{H}, \mathrm{Ar}-\mathrm{CH}_{2}\right), 4.35\left(\mathrm{~d}, 1 \mathrm{H}, \mathrm{C}_{5}-\mathrm{H}, J=4.9 \mathrm{~Hz}\right), 7.06$ $7.33(\mathrm{~m}, 9 \mathrm{H}, \mathrm{Ar}-\mathrm{H}), 9.21$ (bs, $1 \mathrm{H}, \mathrm{NH}) ;{ }^{13} \mathrm{C}-\mathrm{NMR}\left(\mathrm{CDCl}_{3}+\mathrm{DMSO}_{6}\right) \delta$ : $27.8\left(\mathrm{~N}-C H_{3}\right), 28.1\left(\mathrm{~N}-\mathrm{CH}_{3}\right), 52.4\left(\mathrm{C}-2^{\prime}\right), 55.3\left(\mathrm{C}-1^{\prime}\right), 56.8\left(\mathrm{Ar}^{-} \mathrm{CH}_{2}\right), 63.8$ (C-5), 157.4 (C-2), 163.2 (C-6), 174.9 (C-4), 125.1, 125.7, 126.6, 127.4, 128.3, 131.7, 133.8, 139.9; MS m/z: $447\left(\mathrm{M}^{+\cdot}\right)$. Anal. Calcd for $\mathrm{C}_{21} \mathrm{H}_{22} \mathrm{ClN}_{3} \mathrm{O}_{4} \mathrm{~S}: \mathrm{C}, 56.31 ; \mathrm{H}, 4.95 ; \mathrm{N}, 9.38$; Found C, 56.41; H, 4.94; N, 9.45 .

6-Imino-5-[2'-(4-chlorophenylmethylsulfonyl)-1' -(4-chlorophenyl)ethyl]1,3-dimethylpyrimidine-2,4-dione (16b): Light yellow solid, yield 64\%, mp 250-252 ${ }^{\circ} \mathrm{C}$; IR (KBr) cm ${ }^{-1}: 3225(\mathrm{NH}), 1636(\mathrm{C}=\mathrm{O}), 1604(\mathrm{C}=\mathrm{N}), 1318$, $1132\left(\mathrm{SO}_{2}\right) .{ }^{1} \mathrm{H}-\mathrm{NMR}\left(\mathrm{CDCl}_{3}+\mathrm{DMSO}-d_{6}\right) \delta: 2.73\left(\mathrm{~s}, 6 \mathrm{H}, \mathrm{N}-\mathrm{CH}_{3}\right), 3.13(\mathrm{dd}$, $\left.1 \mathrm{H}, \mathrm{C}_{2}^{\prime}-\mathrm{H}, J=4.7,14.6 \mathrm{~Hz}\right), 3.74\left(\mathrm{dd}, 1 \mathrm{H}, \mathrm{C}_{2}^{\prime}-\mathrm{H}, J=9.6,14.4 \mathrm{~Hz}\right), 4.11-$ $4.17\left(\mathrm{~m}, 1 \mathrm{H}, \mathrm{C}_{1}^{\prime}-\mathrm{H}\right), 4.27\left(\mathrm{~s}, 2 \mathrm{H}, \mathrm{Ar}-\mathrm{CH}_{2}\right), 4.34\left(\mathrm{~d}, 1 \mathrm{H}, \mathrm{C}_{5}-\mathrm{H}, J=5.0 \mathrm{~Hz}\right)$, $7.12-7.41(\mathrm{~m}, 8 \mathrm{H}, \mathrm{Ar}-\mathrm{H}), 9.18$ (bs, $1 \mathrm{H}, \mathrm{NH}) ;{ }^{13} \mathrm{C}-\mathrm{NMR}\left(\mathrm{CDCl}_{3}+\mathrm{DMSO}-\right.$ $\left.d_{6}\right) \delta: 28.9\left(\mathrm{~N}-\mathrm{CH}_{3}\right), 29.4\left(\mathrm{~N}-\mathrm{CH}_{3}\right), 53.3\left(\mathrm{C}-2^{\prime}\right), 54.8\left(\mathrm{C}-1^{\prime}\right), 57.3\left(\mathrm{Ar}-\mathrm{CH}_{2}\right)$, 64.2 (C-5), 157.0 (C-2), 162.6 (C-6), 175.3 (C-4), 126.4, 126.9, 127.2, 129.3, 130.4, 131.3, 133.6, 138.7; MS m/z: $481\left(\mathrm{M}^{+*}\right)$. Anal. Calcd for $\mathrm{C}_{21} \mathrm{H}_{21} \mathrm{Cl}_{2} \mathrm{~N}_{3} \mathrm{O}_{4} \mathrm{~S}$ : C, 52.29; H, 4.39; N, 8.71; Found C, 52.21; H, 4.43; N, 8.68.

General Procedure of Synthesis of 6-Amino-5,5-bis-(2'-phenylsulfonylethyl)-2-mercaptopyrimidine-4-one (6)/6-Amino-5-(2'-arylsulfonyl1 '-arylethyl)-2-mercaptopyrimidine-4-one $(17 \mathrm{a}-\mathrm{b}) / 6$-Amino-5-(2'-arylmethylsulfonyl-1'-arylethyl)-2-mercaptopyrimidine-4-one $(18 \mathbf{a}-\mathbf{b})$ To a solution of $\mathbf{1} / \mathbf{7} / \mathbf{8}(0.01 \mathrm{~mol})$ in $\mathrm{EtOH}(20 \mathrm{ml})$, thiourea $(0.01 \mathrm{mmol})$ and piperidine $(5 \mathrm{ml})$ were added and refluxed for $7-12 \mathrm{~h}$. The reaction mixture was cooled, poured onto crushed ice containing conc. $\mathrm{HCl}$ and extracted with ethyl acetate. The organic layer was washed with brine and dried over anhydrous $\mathrm{Na}_{2} \mathrm{SO}_{4}$. The solvent was removed with rotary evaporator. The resulted solid was purified by recrystallization from $\mathrm{MeOH}$.

6-Amino-5,5-bis-(2'-phenylsulfonylethyl)-2-mercaptopyrimidine-4-one (6): White solid, yield $68 \%, \mathrm{mp} 269-271^{\circ} \mathrm{C}$; IR $(\mathrm{KBr}) \mathrm{cm}^{-1}: 3462,3357$ $(\mathrm{NH}), 2558(\mathrm{SH}), 1630(\mathrm{C}=\mathrm{O}), 1616(\mathrm{C}=\mathrm{N}), 1338,1142\left(\mathrm{SO}_{2}\right) .{ }^{1} \mathrm{H}-\mathrm{NMR}$ $\left(\mathrm{CDCl}_{3}+\mathrm{DMSO}-d_{6}\right) \delta: 1.35(\mathrm{~s}, 1 \mathrm{H}, \mathrm{SH}), 1.83-1.94\left(\mathrm{~m}, 2 \mathrm{H}, \mathrm{C}_{1}^{\prime}-\mathrm{H}\right), 2.14$ $2.22\left(\mathrm{~m}, 2 \mathrm{H}, \mathrm{C}_{1}^{\prime}-\mathrm{H}\right), 2.89-3.05\left(\mathrm{~m}, 4 \mathrm{H}, \mathrm{C}_{2}^{\prime}-\mathrm{H}\right), 5.97\left(\mathrm{bs}, 2 \mathrm{H}, \mathrm{NH}_{2}\right), 7.37$ 
$7.86(\mathrm{~m}, 10 \mathrm{H}, \mathrm{Ar}-\mathrm{H}) ;{ }^{13} \mathrm{C}-\mathrm{NMR}\left(\mathrm{CDCl}_{3}+\mathrm{DMSO}-d_{6}\right) \delta: 22.9\left(\mathrm{C}-1^{\prime}\right), 43.2$ (C-5), 49.1 (C-2'), 163.8 (C-6), 179.1 (C-4), 187.5 (C-2), 127.2, 129.4, 133.4, 137.5; MS m/z: $479\left(\mathrm{M}^{+\cdot}\right)$. Anal. Calcd for $\mathrm{C}_{20} \mathrm{H}_{21} \mathrm{~N}_{3} \mathrm{O}_{5} \mathrm{~S}_{3}$ : C, 50.09; H, 4.41; N, 8.76.; Found C, 50.00; H, 4.39; N, 8.84.

6-Amino-5-(2'-phenylsulfonyl-1' -phenylethyl)-2-mercaptopyrimidine-4one (17a): White crystals, yield $65 \%, \mathrm{mp} 285-287^{\circ} \mathrm{C}$; IR $(\mathrm{KBr}) \mathrm{cm}^{-1}$ : 3462, $3357(\mathrm{NH}), 2557(\mathrm{SH}), 1638(\mathrm{C}=\mathrm{O}), 1610(\mathrm{C}=\mathrm{N}), 1325,1137\left(\mathrm{SO}_{2}\right)$ ${ }^{1} \mathrm{H}-\mathrm{NMR}\left(\mathrm{CDCl}_{3}+\mathrm{DMSO}-d_{6}\right) \delta: 1.38(\mathrm{~s}, 1 \mathrm{H}, \mathrm{SH}), 3.01\left(\mathrm{dd}, 1 \mathrm{H}, \mathrm{C}_{2}^{\prime}-\mathrm{H}\right.$, $J=4.6,14.4 \mathrm{~Hz}), 3.75\left(\mathrm{dd}, 1 \mathrm{H}, \mathrm{C}_{2}^{\prime}-\mathrm{H}, J=9.7,14.5 \mathrm{~Hz}\right), 4.14-4.21(\mathrm{~m}, 1 \mathrm{H}$ $\left.\mathrm{C}_{1}^{\prime}-\mathrm{H}\right), 4.31\left(\mathrm{~d}, 1 \mathrm{H}, \mathrm{C}_{5}-\mathrm{H}, J=5.2 \mathrm{~Hz}\right), 5.77\left(\mathrm{bs}, 2 \mathrm{H}, \mathrm{NH}_{2}\right), 7.11-7.84(\mathrm{~m}$ $10 \mathrm{H}, \mathrm{Ar}-\mathrm{H}) ;{ }^{13} \mathrm{C}-\mathrm{NMR}\left(\mathrm{CDCl}_{3}+\mathrm{DMSO}-d_{6}\right) \delta: 52.0\left(\mathrm{C}-2^{\prime}\right), 53.4\left(\mathrm{C}-1^{\prime}\right), 63.7$ (C-5), 162.9 (C-6), 178.3 (C-4), 186.8 (C-2), 125.2, 126.0, 126.6, 127.5, 128.4, 132.3, 137.6, 140.2; MS m/z: $387\left(\mathrm{M}^{+\cdot}\right)$. Anal. Calcd for $\mathrm{C}_{18} \mathrm{H}_{17} \mathrm{~N}_{3} \mathrm{O}_{3} \mathrm{~S}_{2}: \mathrm{C}, 55.79 ; \mathrm{H}, 4.42 ; \mathrm{N}, 10.84$; Found $\mathrm{C}, 55.73 ; \mathrm{H}, 4.45 ; \mathrm{N}$ 10.93 .

6-Amino-5-[2'-phenylsulfonyl-1'-(4-chlorophenyl)ethyl]-2-mercaptopyrimidine-4-one $(\mathbf{1 7 b})$ : White crystals, yield $70 \%, \mathrm{mp} 276-278^{\circ} \mathrm{C}$; IR $(\mathrm{KBr}) \mathrm{cm}^{-1}: 3450,3338(\mathrm{NH}), 2545(\mathrm{SH}), 1645(\mathrm{C}=\mathrm{O}), 1606(\mathrm{C}=\mathrm{N})$, $1316,1134\left(\mathrm{SO}_{2}\right) .{ }^{1} \mathrm{H}-\mathrm{NMR}\left(\mathrm{CDCl}_{3}+\mathrm{DMSO}-d_{6}\right) \delta: 1.35(\mathrm{~s}, 1 \mathrm{H}, \mathrm{SH}), 3.08$ $\left(\mathrm{dd}, 1 \mathrm{H}, \mathrm{C}_{2}^{\prime}-\mathrm{H}, J=4.8,14.2 \mathrm{~Hz}\right), 3.77\left(\mathrm{dd}, 1 \mathrm{H}, \mathrm{C}_{2}^{\prime}-\mathrm{H}, J=9.8,14.3 \mathrm{~Hz}\right.$ ), $4.16-4.22\left(\mathrm{~m}, 1 \mathrm{H}, \mathrm{C}_{1}^{\prime}-\mathrm{H}\right), 4.37\left(\mathrm{~d}, 1 \mathrm{H}, \mathrm{C}_{5}-\mathrm{H}, J=5.1 \mathrm{~Hz}\right), 5.85(\mathrm{bs}, 2 \mathrm{H}$ $\left.\mathrm{NH}_{2}\right), 7.05-7.96(\mathrm{~m}, 9 \mathrm{H}, \mathrm{Ar}-\mathrm{H}) ;{ }^{13} \mathrm{C}-\mathrm{NMR}\left(\mathrm{CDCl}_{3}+\mathrm{DMSO}-d_{6}\right) \delta: 53.1(\mathrm{C}-$ $2^{\prime}$ ), 55.8 (C-1'), 62.9 (C-5), 163.7 (C-6), 176.2 (C-4), 187.4 (C-2), 125.5 126.3, 127.2, 129.6, 131.5, 132.2, 138.9, 140.6; MS m/z: $421\left(\mathrm{M}^{+}\right)$. Anal. Calcd for $\mathrm{C}_{18} \mathrm{H}_{16} \mathrm{ClN}_{3} \mathrm{O}_{3} \mathrm{~S}_{2}$ : C, 51.24; H, 3.82; N, 9.96; Found C, 51.32; H, $3.86 ; \mathrm{N}, 10.04$.

6-Amino-5-[2'-(4-chlorophenylsulfonyl)-1'-phenylethyl]-2-mercaptopyrimidine-4-one (18a): White crystals, yield $75 \%, \mathrm{mp} 204-206^{\circ} \mathrm{C}$; IR $(\mathrm{KBr})$ $\mathrm{cm}^{-1}: 3457,3351(\mathrm{NH}), 2543(\mathrm{SH}), 1634(\mathrm{C}=\mathrm{O}), 1608(\mathrm{C}=\mathrm{N}), 1321,1131$ $\left(\mathrm{SO}_{2}\right) .{ }^{1} \mathrm{H}-\mathrm{NMR}\left(\mathrm{CDCl}_{3}+\mathrm{DMSO}-d_{6}\right) \delta: 1.32(\mathrm{~s}, 1 \mathrm{H}, \mathrm{SH}), 3.05\left(\mathrm{dd}, 1 \mathrm{H}, \mathrm{C}_{2}^{\prime}-\right.$ $\mathrm{H}, J=4.7,14.5 \mathrm{~Hz}), 3.74\left(\mathrm{dd}, 1 \mathrm{H}, \mathrm{C}_{2}^{\prime}-\mathrm{H}, J=9.4,14.4 \mathrm{~Hz}\right), 4.18-4.23(\mathrm{~m}$, $\left.1 \mathrm{H}, \mathrm{C}_{1}^{\prime}-\mathrm{H}\right), 4.29$ (s, 2H, Ar- $\left.\mathrm{CH}_{2}\right), 4.33\left(\mathrm{~d}, 1 \mathrm{H}, \mathrm{C}_{5}-\mathrm{H}, J=5.3 \mathrm{~Hz}\right), 5.78$ (bs, $\left.2 \mathrm{H}, \mathrm{NH}_{2}\right), 7.04-7.37(\mathrm{~m}, 9 \mathrm{H}, \mathrm{Ar}-\mathrm{H}) ;{ }^{13} \mathrm{C}-\mathrm{NMR}\left(\mathrm{CDCl}_{3}+\mathrm{DMSO}-d_{6}\right) \delta$ : $52.9\left(\mathrm{C}-2^{\prime}\right), 54.7\left(\mathrm{C}-1^{\prime}\right), 57.6\left(\mathrm{Ar}^{-} \mathrm{CH}_{2}\right), 63.7(\mathrm{C}-5), 162.7$ (C-6), $175.5(\mathrm{C}-$ 4), 185.9 (C-2), 125.3, 126.6, 127.1, 128.6, 129.5, 131.7, 133.9, 141.5; MS m/z: $435\left(\mathrm{M}^{+\cdot}\right)$. Anal. Calcd for $\mathrm{C}_{19} \mathrm{H}_{18} \mathrm{ClN}_{3} \mathrm{O}_{3} \mathrm{~S}_{2}: \mathrm{C}, 52.35 ; \mathrm{H}, 4.16 ; \mathrm{N}, 9.64$; Found $\mathrm{C}, 52.43 ; \mathrm{H}, 4.18 ; \mathrm{N}, 9.60$.

6-Amino-5-[2'-(4-chlorophenylsulfonyl)-1' -(4-chlorophenyl)ethyl]-2mercaptopyrimidine-4-one $(\mathbf{1 8 b})$ : White solid, yield $72 \%$, mp $254-256{ }^{\circ} \mathrm{C}$; IR $(\mathrm{KBr}) \mathrm{cm}^{-1}: 3441,3345(\mathrm{NH}), 2559(\mathrm{SH}), 1642(\mathrm{C}=\mathrm{O}), 1614(\mathrm{C}=\mathrm{N})$, 1330, $1138\left(\mathrm{SO}_{2}\right) .{ }^{1} \mathrm{H}-\mathrm{NMR}\left(\mathrm{CDCl}_{3}+\mathrm{DMSO}-d_{6}\right) \delta: 1.37(\mathrm{~s}, 1 \mathrm{H}, \mathrm{SH}), 3.02$ $\left(\mathrm{dd}, 1 \mathrm{H}, \mathrm{C}_{2}^{\prime}-\mathrm{H}, J=4.9,14.3 \mathrm{~Hz}\right), 3.71\left(\mathrm{dd}, 1 \mathrm{H}, \mathrm{C}_{2}^{\prime}-\mathrm{H}, J=9.5,14.1 \mathrm{~Hz}\right)$, $4.21-4.26\left(\mathrm{~m}, 1 \mathrm{H}, \mathrm{C}_{1}^{\prime}-\mathrm{H}\right), 4.28\left(\mathrm{~s}, 2 \mathrm{H}, \mathrm{Ar}-\mathrm{CH}_{2}\right), 4.30\left(\mathrm{~d}, 1 \mathrm{H}, \mathrm{C}_{5}-\mathrm{H}\right.$, $J=5.4 \mathrm{~Hz}$ ), 5.85 (bs, $\left.2 \mathrm{H}, \mathrm{NH}_{2}\right), 7.10-7.41(\mathrm{~m}, 8 \mathrm{H}, \mathrm{Ar}-\mathrm{H}) ;{ }^{13} \mathrm{C}-\mathrm{NMR}$ $\left(\mathrm{CDCl}_{3}+\mathrm{DMSO}-d_{6}\right) \delta: 52.6\left(\mathrm{C}-2^{\prime}\right), 53.8\left(\mathrm{C}-1^{\prime}\right), 57.9\left(\mathrm{Ar}^{\prime} \mathrm{CH}_{2}\right), 62.4(\mathrm{C}-5)$, 163.5 (C-6), 176.4 (C-4), 186.7 (C-2), 125.3, 126.2, 127.4, 128.4, 130.8, 131.7, 133.8, 141.3 (aromatic carbons); MS m/z: $469\left(\mathrm{M}^{+\cdot}\right)$. Anal. Calcd for $\mathrm{C}_{19} \mathrm{H}_{17} \mathrm{Cl}_{2} \mathrm{~N}_{3} \mathrm{O}_{3} \mathrm{~S}_{2}: \mathrm{C}, 48.51 ; \mathrm{H}, 3.64 ; \mathrm{N}, 8.93$. Found $\mathrm{C}, 48.57 ; \mathrm{H}, 3.63 ; \mathrm{N}$, 8.98 .

Antimicrobial Testing The compounds 2-6 and 9-18 were dissolved in DMSO at different concentrations of 100,200 and $800 \mu \mathrm{g} / \mathrm{ml}$.

Antibacterial and Antifungal Assays Preliminary antimicrobial activities of compounds $\mathbf{2}-\mathbf{6}$ and $\mathbf{9 - 1 8}$ were tested by agar disc-diffusion method. Sterile filter paper discs $(6 \mathrm{~mm}$ diameter $)$ moistened with the test compound solution in DMSO of specific concentration $100 \mu \mathrm{g}$ and 200 $\mu \mathrm{g} /$ disc were carefully placed on the agar culture plates that had been previously inoculated separately with the microorganisms. The plates were incubated at $37{ }^{\circ} \mathrm{C}$ and the diameter of the growth inhibition zones were measured after $24 \mathrm{~h}$. in case of bacteria and after $48 \mathrm{~h}$ in case of fungi.

The MICs of the compounds assays were carried out using microdilution susceptibility method. Chloramphenicol was used as reference antibacterial agent. Ketoconazole was used as reference antifungal agent. The test compounds, chloramphenicol and ketoconazole were dissolved in DMSO at concentration of $800 \mu \mathrm{g} / \mathrm{ml}$. The twofold dilution of the solution was prepared $(400,200,100,50,25,12.5,6.25)$. The microorganism suspensions were inoculated to the corresponding wells. The plates were incubated at $36^{\circ} \mathrm{C}$ for 24 and $48 \mathrm{~h}$ for bacteria and fungi, respectively. The minimum inhibitory concentrations of the compounds were recorded as the lowest concentration of each chemical compounds in the tubes with no turbidity (i.e. no growth) of inoculated bacteria/fungi.

Antioxidant Testing The compounds 2-6 and 9-18 are tested for antioxidant property by nitric oxide and DPPH methods.

Assay for Nitric Oxide (NO) Scavenging Activity Sodium nitroprusside $(5 \mu \mathrm{M})$ in phosphate buffer $\mathrm{pH} 7.4$ was incubated with $100 \mu \mathrm{M}$ concen- tration of test compounds dissolved in a suitable solvent (dioxane/methanol) and tubes were incubated at $25^{\circ} \mathrm{C}$ for $120 \mathrm{~min}$. Control experiment was conducted with equal amount of solvent in an identical manner. At intervals, $0.5 \mathrm{ml}$ of incubation solution was taken and diluted with $0.5 \mathrm{ml}$ of griess reagent ( $1 \%$ sulfanilamide, $0.1 \% \mathrm{~N}$-naphthylethylenediamine dihydrochloride and $2 \% o$-phosphoric acid dissolved in distilled water). The absorbance of the chromophore formed during diazotization of nitrite with sulfanilamide and subsequent $N$-naphthylethylenediamine dihydrochloride was read at $\lambda 546 \mathrm{~nm}$. The experiment was repeated in triplicate

Reduction of 1,1-Diphenyl-2-picrylhydrazyl (DPPH) Free Radical (DPPH Method) The nitrogen centered stable free radical 1,1-diphenyl-2picrylhydrazyl (DPPH) has often been used to characterize antioxidants. It is reversibly reduced and the odd electron in the DPPH free radical gives a strong absorption maximum at $\lambda 517 \mathrm{~nm}$, which is purple in color. This property makes it suitable for spectrophotometric studies. A radical scavenging antioxidant reacts with DPPH stable free radical and converts into 1,1diphenyl-2-picrylhydrazine. The resulting decolorization is stoichiometric with respect to the number of electrons captured. The change in the absorbance produced in this reaction has been used to measure antioxidant properties.

The solutions of test compounds $(100 \mu \mathrm{M})$ were added to DPPH $(100 \mu \mathrm{M})$ in dioxane/ethanol. The tubes were kept at an ambient temperature for $20 \mathrm{~min}$ and the absorbance was measured at $\lambda 517 \mathrm{~nm}$. The difference between the test and the control experiments was taken and expressed as the per cent scavenging of the DPPH radical.

Acknowledgements The authors are thankful to DST New Delhi, India for the financial assistance under major research project and to $\mathrm{Ch}$. Kishore Kumar, Department of Botany, Sri Venkateswara University, Tirupati, India for his help in antimicrobial testing. One of the authors D.R.C. Venkata Subbaiah is thankful to CSIR, New Delhi, India for the sanction of Senior Research Fellowship.

\section{References}

1) Goodman L. S., Gilman A., "The Pharmacological Basis of Therapeutics," McGraw-Hill, New Delhi, 1991, pp. 358 - 360.

2) Andres G., "Medical Pharmacology," The CV Mosby Company, Saint Louis, 1976, p. 243

3) Foye W. O., "Principles of Medicinal Chemistry," Lea \& Febiger, London, 1989 , p. 159

4) Meyers F. H., Jawetz E., Goldfien A., "Review of Medical Pharmacology," Lange Medical Publications, California, 1976, p. 222.

5) Wilson and Gisvold's, "Text Book of Organic, Medical and Pharmaceutical Chemistry," J. B. Lippincott Co., Philadelphia, New York, 1991, p. 368.

6) Hardman J. G., Limbird L. E., "Goodman \& Gilman's The Pharmacological Basis of Therapeutics," McGraw-Hill, New York, 1996, pp. $471-472$.

7) Cope A. C., Kovacic P., Burg M., J. Am. Chem. Soc., 71, 3658-3662 (1949).

8) Geigy J. R., Swiss, 230367 (1944), [Chem. Abstr., 43, 3472i (1949)]

9) Boarland M. P. V., McOmie J. F. W., Timms R. N., J. Chem. Soc., 1952 , 4691-4695 (1952).

10) Buchi J., Ammnn J., Lieberherr R., Eichenberger E., Helv. Chim. Acta, 36, 75-78 (1953).

11) Kornet M. J., Thorstenson J. H., Lubawy W. C., J. Pharm. Sci., 63, 1090-1093 (1974).

12) Richon A. B., Maragoudakis M. E., Wasvary J. S., J. Med. Chem., 25, $745-747(1982)$.

13) Shinkai H., Onogi S., Tanaka M., Shibata T., Iwao M., Wakitani K., Uchida I., J. Med. Chem., 41, 1927-1933 (1998).

14) Nagai A., Matsushita Y., Ono N., Takechi Y., Jpn. Kokai Tokkyo JP 04173780 (1992) [Chem. Abstr., 117, 212485 (1992)].

15) Dannahardt G., Kiefer W., Kramer G., Maehrlein S., Nowe U., Fiebich B., Eur. J. Med. Chem., 35, 499-510 (2000).

16) Padmavathi V., Venkata Subbaiah D. R. C., Balaiah A., Chandra Obula Reddy B., Padmaja A., Indian J. Chem., 44B, 2569-2574 (2005).

17) National Committee for Clinical Laboratory Standards (NCCLS) Approved standard document M-7A, Villanova, PA, 1985.

18) Murray P. R., Baron E. J., Pfaller M. A., Tenover F. C., Yolken R. H., "Manual of Clinical Microbiology," ed. by Wood G. L., Washington J. A., American Society for Microbiology, Washington DC, 1995.

19) Shirwaiker A., Rajendran K., Dinesh kumar C., Indian J. Exp. Biol., 42, 803-807 (2004).

20) Babu B. H., Shailesh B. S., Paddikala J., Fitotherapia, 72, 272-279 (2001).

21) Kato K., Terao S., Shimamoto N., Hirata M., J. Med. Chem., 31, 793798 (1988). 